\title{
HÉRNIAS INTRA-RAQUIDIANAS DOS DISCOS INTERVERTEBRAIS LOMBARES. RESÜLTADOS DA EXCISÃO EM 128 CASOS
}

\author{
Rolando A. Tenuto *
}

Os conhecimentos sôbre as hérnias intra-raquidianas dos discos intervertebrais lombares representam notável progresso para o diagnóstico etiológico e para a terapêutica de grande número de casos de lombalgias e de radiculalgias nos membros inferiores, que eram, anteriormente, catalogados como essenciais, idiopáticos ou criptogenéticos e para os quais eram invocadas causas as mais diversas - neurites reumatismais, infecções a vírus, flebectasias radiculares, neurodocites - tôdas sem base em documentação suficiente.

Sòmente nos dois últimos decênios foram estabelecidas as bases seguras para o diagnóstico correto das hérnias dos discos intervertebrais lombares. Trabalhos de índole clínica, experimental, radiológica, cirúrgica e anátomopatológica - demonstrando a possibilidade de prolapsos de discos intervertebrais lombares para o interior do canal raquidiano, mostrando o mecanismo de produção dessa procidência e seu modo de ação comprimindo as raizes raquidianas - contribuíram para dar à protrusão discal o caráter de entidade nosológica bem definida, indicando os recursos lógicos para o tratamento.

Restringindo ao essencial os dados que orientam o diagnóstico, procuraremos salientar, neste trabalho, os resultados do tratamento cirúrgico, cujo emprêgo ainda dá margem a controvérsia; discutem-se as vantagens da intervenção cirúrgica, apontando para os casos em que o tratamento conservador deu resultados compensadores e estabelece-se controvérsia entre ortopedistas e neurocirurgiões quanto à tática operatória. Nossa experiência nos leva a adotar uma posição eclética em relação às duas questões.

Admitimos que, em numerosos casos que apresentam exclusivamente sintomatologia dolorosa subjetiva, deve ser tentado o tratamento conservador; entretanto, a intervenção operatória tem indicação formal nos casos em que existam sinais sensitivo-motores objetivos de sofrimento radicular e nos quais, portanto, qualquer contemporização será prejudicial.

Tese para concurso à Docência Livre de Clínica Neurológica na Fac. Med. da Univ. de São Paulo (novembro de 1958).

* Assistente extranumerário da Clínica Neurológica da Fac. Med. da Univ. de São Paulo (Prof. Adherbal Tolosa); Chefe da Seccão de Neurocirurgia. 
Cremos que tanto os neurocirurgiões como os ortopedistas são igualmente aptos para a excisão de hérnias intra-raquidianas de discos intervertebrais. Defendemos, entretanto, a idéia de que a tática cirúrgica adotada atualmente para essas excisões, quando não ocorram complicações, dispensa a artródese imediata recomendada por alguns ortopedistas, receosos de que a excisão da hérnia altere a estabilidade da coluna vertebral; a artródese poderá ser feita, em segundo tempo, apenas nos casos em que as circunstâncias a exigirem.

Nos casos em que existam elementos sugerindo a presença de grandes hérnias discais comprimindo em massa as raízes da cauda eqüina, ou naqueles em que haja discordância entre os dados clínicos e os exames radiológicos, sugerindo existência de neoplasias do sistema nervoso - casos nos quais podem ocorrer, no ato operatório, situações que exijam atuação intradural - as intervenções devem ser efetuadas por neurocirurgiões. Muitas vêzes, o neurocirurgião é levado à abertura do estojo dural, ou mesmo, à secção de uma raiz raquidiana macroscỏpicamente alterada quando não se convence de que a hérnia encontrada é causa suficiente da sintomatologia dolorosa apresentada pelo paciente; a experiência pessoal e os conhecimentos neurológicos do operador muito o auxiliarão em tais circunstâncias, orientando sôbre a melhor tática a adotar.

O material utilizado nesta tese abrange casos relativos a pacientes internados na Clínica Neurológica (Prof. Adherbal Tolosa) e no Departamento de Cirurgia do Hospital das Clínicas da Faculdade de Medicina da Universidade de São Paulo, assim como casos de clínica particular. De 1945 até junho de 1957 operamos 571 pacientes portadores de hérnias intra-raquidianas de discos intervertebrais lombares.

Devem ser lembradas, entretanto, as dificuldades quanto ao seguimento de casos operatórios, seja porque o doente curado não se dá ao trabalho de retornar para reexame, seja porque, em caso de recidiva e desanimado, êle procura recursos terapêticos em outras fontes. Nossas conclusões comportarão resultados verificados nos casos de hérnias discais, nos quais foi possivel um seguimento pós-operatório durante o prazo mínimo de um ano: êste foi o critério que nos guiou para apresentar os resultados obtidos em apenas 128 casos, dos 571 pacientes que foram operados de hérnias de discos intervertebrais lombares.

PORMENORES DE ANATOMIA TOPOGRÁFICA DOS DISCOS INTERVERTEBRAIS E DAS RAfZES RAQUIDIANAS DA REGIAO LOBOSSACRA. LOCALIZAÇÃO DAS HERNIAS DISCAIS NOS 128 CASOS ESTUDADOS

Qualquer estudo sôbre o tratamento cirúrgico das hérnias intra-raquidianas de discos intervertebrais lombares exige a recapitulação sumária de alguns pormenores anátomo-fisiológicos para a compreensão da sintomatologia e para a orientação do tratamento. 
Na região lombar, a forma e as dimensões do canal raquidiano, normalmente, variam muito pouco. O ligamento amarelo e as lâminas vertebrais constituem a parede posterior dêsse canal; o mesmo ligamento amarelo, os pedículos e as articulações vertebrais posteriores constituem suas paredes laterais; os corpos vertebrais e a porção posterior dos discos intervertebrais, recobertos pelo ligamento longitudinal posterior, constituem a parede anterior.

Os buracos de conjugação, ou orifícios laterais do canal raquidiano, são canais curtos, constituidos pela superposição de dois pedículos articulares vizinhos; êsses orifícios são limitados, posteriormente, pelas apófises articulares e, anteriormente, pelos corpos vertebrais e porção posterior dos discos intervertebrais.

Os discos intervertebrais, atuando como coxins elásticos entre os corpos vertebrais, são constituídos por três tecidos: um, em forma de lâmina, representado pelas cartilagens hialinas que estão em contacto com os corpos vertebrais; o segundo, representado por um sólido anel elástico, o anel fibroso; o terceiro, chamado núcleo pulposo e circundado pelo anel fibroso, tem a estrutura de um gel aquoso, composto de material colágeno denso (Hirsch ${ }^{50}$ ). Os discos intervertebrais são recobertos na sua face dorsal, isto é, naquela que contribui para a formação do canal raquidiano, pelo ligamento longitudinal posterior. No adulto, êsses discos são desprovidos de vasos.

No ligamento longitudinal posterior existem numerosas terminações nervosas, ao passo que, no disco propriamente dito, não são descritas terminações nervosas sensitivas, embora alguns autores refiram sua existência na porção mais externa e posterior do anel fibroso.

Quando submetido a uma pressão, o disco intervertebral sofre pequena mudança de forma, retornando à forma habitual desde que a fôrça aplicada não ultrapasse seu limite da elasticidade; a ação mecânica exercida, nestas condições, sôbre as terminações nervosas sensitivas do ligamento longitudinal posterior é pequena e não provoca dor. Se, entretanto, o disco intervertebral estiver alterado, essa mesma pressão pode ocasionar a passagem progressiva, através do anel fibroso, do núcleo pulposo, que termina por entrar em contacto com o ligamento longitudinal posterior. Este, sendo pouco resistente, sobretudo em suas partes laterais, é insuficiente para contê-lo; consequientemente, haverá abaulamento com distensão de estruturas nervosas, ocasionando dor (Hirsch ${ }^{50}$ ). Outras vêzes, o ligamento longitudinal posterior se rompe e o conteúdo discal penetra no canal raquidiano. Entretanto, isto não ocorre comumente, sendo mais freqüente que o ligamento longitudinal posterior, na impossibilidade de conter a progressão da hérnia, se distenda, tornando-se abaulado e podendo, até, destacar-se de suas inserções nas borđas das vértebras. Nessas partes traumatizadas em suas inserçōes instalam-se calcificaçōes secundárias, constituindo as bordas escleróticas das vértebras, que podem ser observadas tanto pelo exame radiológico como durante as intervenções cirúrgicas. E evidente que as intervenções excisando hérnias discais deverão ser completadas pela retirada dessas excrescências ósseas que, por si sós, ocasionam dor.

A relação entre as raizes raquidianas e os discos intervertebrais lombares é importante sob os pontos de vista clinico e cirúrgico. Abandonando o saco dural e antes de atravessarem os buracos de conjugação, as raizes raquidianas percorrem curto trajeto dentro do canal raquidiano. Nesse trajeto, de cima para baixo e de dentro para fora, elas cruzam o têrço lateral da face posterior do disco intervertebral situado abaixo do corpo vertebral, ao nivel do qual emergiram do saco dural. Dêsse modo, nos casos de hérnias intra-raquidianas dos discos intervertebrais lombares, e notadamente das hërnias dos discos entre $L v_{4}-L_{5}$ e $L v_{5}-S v_{1}$, as raízes raquidianas comprimidas por êsses prolapsos seriam, respectivamente, a quinta lombar e a primeira sacra.

A quarta raiz lombar freqüentemente também emerge acima do disco intervertebral entre $\mathrm{Lv}_{3}$ e $\mathrm{Lv}_{4}$ (Armstrong ${ }^{6}$ ); entretanto, Falconer, McGeorge e Begg ${ }^{3.3}$ 
assinalam que as raizes raquidianas acima da quinta lombar nāo mantêm esta re lação topográfica com os discos intervertebrais. Barbosa ${ }^{9}$ também assinala a falta de relação topográfica entre as raízes raquidianas $L_{1}, L_{2}$ e $L_{3}$ e os discos intervertebrais lombares, admitindo que sòmente nos buracos de conjugação essas raizes entram em contacto com os discos respectivos. Küs e De Sèze ${ }^{60}$ descrevem variedades anatômicas em que a emergência das raizes $L_{5}$ e $S_{1}$ ao nível do saco dural é muito alta; em alguns casos a raiz $L_{5}$ emergeria acima do terceiro disco lombar, ao passo que a raiz $S_{1}$ abandonaria o saco dural acima do quarto disco intervertebral lombar.

Tal seja a localização do prolapso discal ou quando a saliência compressiva é grande, deformando o saco dural, duas ou mais raízes raquidianas podem ser comprimidas; ocorre, então, sintomatologia plurirradicular, que pode despertar a dúvida de que se trate de prolapso de um só ou de vários discos intervertebrais, ou ainda, de que a afecção causal seja de caráter neoplásico.

Nos 128 casos que serviram de material para êste trabalho, as hérnias discais distribuíam-se do seguinte modo:

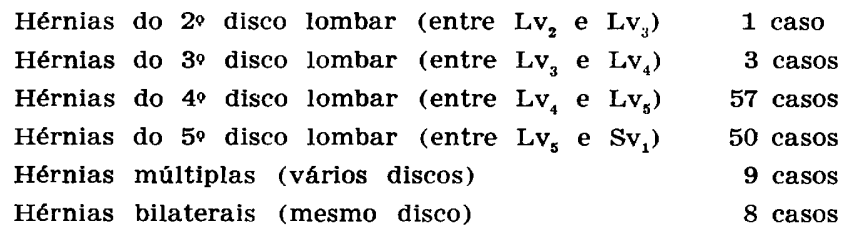

Para facilidade de compreensão usaremos nomenclatura já consagrada para designar vértebras $\left(L v_{1}, L v_{2}, L v_{3}, L v_{4}, L v_{5}\right.$ e $\left.S v_{1}\right)$, diferençando-a da designação das raizes raquidianas $\left(\mathrm{L}_{1}, \mathrm{~L}_{2}, \mathrm{~L}_{3}, \mathrm{~L}_{4}, \mathrm{~L}_{5}, \mathrm{~S}_{1}\right)$.

INCIDENCIA E DIAGNOSTICO DAS HERNIAS DE DISCOS INTERVERTEBRAIS LOMBARES. EXAMES COMPLEMENTARES. DIAGNOSTICO DIFERENCIAL

Não é nosso propósito analisar todos os sintomas decorrentes de alterações que acometem os discos intervertebrais, mas apenas salientar alguns aspectos de importância para valorizar os resultados de um método operatório para tratamento de herniações discais. Procuraremos focalizar a atenção sôbre alguns elementos que conduzem ao diagnóstico das hérnias intraraquidianas dos discos intervertebrais lombares, salientando os dados encontrados nos 128 casos que utilizamos para êste trabalho.

Incidência quanto à idade $e$ sexo - O sexo e a idade dos 128 pacientes aqui considerados estão assinalados na tabela 1 , onde pode ser verificada a maior incidência no sexo masculino, possivelmente ligada ao exercício de trabalhos mais árduos e à maior freqüência dos traumatismos da coluna vertebral. A incidência da afecção no que diz respeito à idade evidencia uma preponderância entre 30 e 39 anos; entre nossos pacientes o mais moço tinha 21 anos e o mais velho, 72 anos de idade. 


\begin{tabular}{|c|c|c|}
\hline \multicolumn{3}{|l|}{ Sexo: } \\
\hline Feminino & 45 & casos \\
\hline Masculino & 83 & casos \\
\hline \multicolumn{3}{|l|}{ Idade: } \\
\hline 20 a 29 anos & 22 & casos \\
\hline 30 a 39 anos & 50 & casos \\
\hline 40 a 49 anos & 29 & casos \\
\hline 50 a 59 anos & 20 & casos \\
\hline 60 a 69 anos & $\mathbf{5}$ & casos \\
\hline 70 a 79 anos & 2 & casos \\
\hline
\end{tabular}

Tabela 1 - Distribuiçăo quanto ao sexo e idade em 128 casos.

Incidência de traumatismos - Nos comemorativos dos pacientes portadores de hérnias de discos intervertebrais lombares é freqüente a menção a traumatismos ou esforços musculares violentos, anteriores ou concomitantes ao início da sintomatologia dolorosa. Segundo alguns, isto se verificaria na maioria dos casos (Permin ${ }^{82}$, Spurling ${ }^{95}$, Hyndman e Steindler ${ }^{52}$ ); outros mencionam, como fatôres ocasionais mais freqüentes, os traumatismos de pouca intensidade mas repetidos (Love ${ }^{68}$, Delitala ${ }^{29}$ ). No presente trabalho, referências a traumatismos intensos ou a esforços musculares violentos constam em 63 casos, o que dá uma percentagem quase igual $(49,21 \%)$ àquela dada pelos casos em que não houve referência a êsse fator $(50,78 \%)$. Referências a esfôrço muscular violento ou a traumatismo precedendo imediatamente o início da sintomatologia, embora não constituam elementos imprescindiveis para o diagnóstico de certeza, têm grande valor para o diagnóstico de presunção.

Sintomatologia dolorosa - Ảs vêzes, o diagnóstico de hérnias intra-raquidianas de discos intervertebrais lombares é fácil, sendo fator fundamental a anamnese, com a descrição detalhada da sintomatologia dolorosa subjetiva.

Lombalgia, como sintoma único no início da afeç̧ão, é a queixa mais comum. Algumas vêzes, a dor é intensa e acompanhada de espasmos musculares, instalando-se de modo súbito, incapacitando o paciente para qualquer atividade; outras vêzes, a dor é menos intensa, persistindo quase inalterada por vários meses ou anos, ou apresentando períodos de remissão e exacerbação. Poucas vêzes, entretanto, assinalamos lombalgia isolada durante todo o evolver da moléstia; em geral, a encontramos associada a dôres nos membros inferiores.

Dor nos membros inferiores, difusa ou localizada no território da distribuição de uma ou mais raízes raquidianas (radiculalgia), não acompanhada de dor lombar, também pode constituir a manifestação inicial da afecção, embora seja pouco freqüente. 
No que diz respeito à difusão ou não da dor, podem apresentar-se duas eventualidades: a) em pequena percentagem de casos, a dor permanece restrita à região lombar durante todo o evolver da moléstia; b) na maioria das vêzes, após um período de lombalgia, permanente ou com remissões, instala-se dor num ou em ambos os membros inferiores. No início, essa dor pode permanecer durante algum tempo localizada em um território limitado (nádega ou face posterior da côxa), para depois adquirir caráter radicular, estendendo-se às áreas de distribuição dos nervos ciaticopopliteos externo e interno. Ocasionalmente, a dor, mesmo em casos de hérnia discal única, acomete ambos os membros inferiores, simultânea ou sucessivamente.

Lombalgia e dor num membro inferior

Lombalgia e dor nos membros inferiores

Lombalgia isolada

Dor localizada sòmente num membro inferior

\section{4 casos \\ 8 casos \\ 8 casos \\ 15 casos}

\footnotetext{
Tabela 2 - Distribuicão da dor no momento do exame em 125 casos (três pacientes não se queixavam de dôres no momento em que foram examinados, sendo operados por apresentarem déficits motores).
}

A distribuição radicular da dor é importante para o diagnóstico de localização; contudo, nem sempre êsse dado indica precisamente o nivel da herniação discal, como ocorre, por exemplo, nos casos de hérnias bilaterais do mesmo disco intervertebral ou nos de hérnias de vários discos com sintomatologia monorradicular (tabela 3), ou quando, embora existindo a manifestação dolorosa radicular, o disco prolabiado se encontra em lugar diverso daquele indicado por êsse dado clínico (tabela 4).

\section{Hérnias bilaterais do mesmo disco}

Radiculalgia unilateral

3 casos

Radiculalgia bilateral

2 casos

Hérnias simultâneas de vários discos

Dor com distribuição monorradicular

5 casos

Dor com distribuição birradicular unilateral

2 casos

Tabela 3 - Localização da dor nos membros inferiores em 12 casos de hérnias bilaterais do mesmo disco e/ou de hérnias de vários discos. Dos 17 casos em que foram encontradas hérnias bilaterais ou de vários discos intervertebrais, em 3 havia apenas referência a lombalgia sem irradiação para os membros inferiores e, em 2 outros, havia apenas dôres difusas nos membros inferiores sem distribuição de caráter radicular típico. 


\begin{tabular}{|c|c|c|c|c|c|c|c|c|}
\hline & \multirow{2}{*}{ Disco herniado } & \multicolumn{4}{|c|}{$\begin{array}{c}\text { Dermatoma doloroso } \\
\text { Raiz }\end{array}$} & \multicolumn{3}{|c|}{$\begin{array}{c}\text { No de casos } \\
\text { Correlação }\end{array}$} \\
\hline & & $\mathrm{L}_{3}$ ou $\mathrm{L}_{1}$ & $\mathrm{~L}_{5}$ & $S_{1}$ & $\mathrm{~L}_{5}$ ou $\mathrm{S}_{1}$ & certa & errada & duvidosa \\
\hline $2^{\circ}$ & lombar ( 1 caso ) & 1 & & & & 1 & & \\
\hline $3^{\circ}$ & lombar ( 3 casos) & - & & & & $\cdots$ & & \\
\hline $4^{\circ}$ & lombar (57 casos) & 1 & 34 & 14 & & 34 & 15 & \\
\hline $5^{\circ}$ & lombar (50 casos) & & 7 & 37 & 2 & 37 & 7 & 2 \\
\hline & Totais & & & & & 72 & 22 & 2 \\
\hline
\end{tabular}

Tabela 4 - Relação entre a distribuição radicular da dor e o nivel do disco herniado (protrusão única) em 96 casos. A análise nesta tabela se refere sòmente a 96 casos, pois, dos 111 pacientes com prolapso único, em 15 não pôde ser estabelecida esta relação porque não havia irradiação, topogràficamente típica, da dor.

Nos 3 casos de hérnia do terceiro disco intervertebral havia dor lombar difusa. Dos 57 casos de hérnia do quarto disco intervertebral, em 5 a dor não era discriminada em dermatoma preciso; em 3 outros não havia queixa de dôres. Dos 50 casos de hérnia do quinto disco lombar, em dois havia apenas referência a lombalgia; em dois outros, não havia discriminação da dor em dermatoma preciso.

Em 70,3\% de nossos casos com radiculalgia nos membros inferiores havia correspondência entre o nível da herniação discal e a distribuição radicular da dor; nos casos restantes não foi possivel, apenas com os dados clínicos, estabelecer essa correlação.

A tabela 5 mostra a duração da sintomatologia antes da intervenção cirúrgica.

$\begin{array}{ll}\text { Menos do que } 6 \text { meses } & 33 \text { casos } \\ \text { Entre } 6 \text { e } 12 \text { meses } & 22 \text { casos } \\ \text { Mais de } 12 \text { meses } & 53 \text { casos } \\ \text { Sem data precisa } & 20 \text { casos }\end{array}$

Tabela 5 - Duração da sintomatologia em 128 casos.

Em alguns casos de lombalgia, a sintomatologia dolorosa desaparece totalmente sem qualquer tratamento e, por isso, alguns autores afirmam que algumas hérnias de discos intervertebrais lombares tendem a regredir espontâneamente. Entretantó, não é acertado considerar como curada uma hérnia discal sómente porque as manifestações dolorosas tenham despercebido, pois podem ocorrer periodos de acalmia da sintomatologia dolorosa sem que haja, necessảriamente, redução anatômica do prolapso. Explica-se o fato admitindo que o núcleo pulposo seja capaz de absorver li- 
quiidos (Scott ${ }^{92}$ ) e, dêsse modo, possa aumentar ou diminuir de volume; um aumento de pressão dentro do anel fibroso, ocasionado nestas circunstâncias, desencadearia dor, que diminuiria de intensidade ou desapareceria com a volta do núcleo às dimensões anteriores, nessas eventualidades, a regressão da sintomatologia dolorosa não se deveria à "cura" da hérnia, pois não havia herniação.

Em alguns casos de hérnias intra-raquidianas de discos intervertebrais, bem comprovados clínica e radiologicamente, a sintomatologia dolorosa pode desaparecer em determinados periodos, permitindo admitir que o edema tenha tido papel saliente na sintomatologia dolorosa, aumentando momentâneamente o tamanho da parte herniada.

Outras circunstâncias são referidas como responsáveis pela remissão dos sintomas dolorosos. Assim, Lasierra ${ }^{62}$ acredita que a parte herniada do núcleo pulposo algumas vêzes possa voltar a seu lugar primitivo; em outras circunstâncias, em virtude de mudança de posição de determinada raiz raquidiana em relação à hérnia, cessaria a compressão e, conseqüentemente, a dor. Embora essas explicações possam ser tidas como verdadeiras, é indubitável que, nesses casos, continuando a agir as mesmas causas traumatizantes e estando diminuída a resisteencia do ligamento longitudinal posterior, a hérnia acabará se refazendo, ao mesmo passo que a raiz raquidiana, sujeita a deslocamentos, pela movimentação da coluna vertebral e dos membros inferiores (Inman-Saunders ${ }^{54}$, O'Connell ${ }^{77}$ ) poderá novamente sem comprimida, com retôrno da sintomatologia.

Dandy ${ }^{21}$, em 1941, aventou o conceito de "concealed disc" (disco oculto), que seria responsável por lombalgias de caráter intermitente, associadas ou não a radiculalgias, sem fornecer critério satisfatório para a identificação de tal entidade mórbida. Após a divulgaçāo dêsse trabalho, dada a grande autoridade do autor, foi realizada enorme série de intervenções cirúrgicas desnecessárias, como comprovaram os maus resultados obtidos. Críticas a êsse procedimento avolumaram-se ulteriormente, servindo os numerosos casos em que tinham sido extraidos discos normais como advertência para a interrupção dessa fase desastrosa da cirurgia.

Lindblom e Hultqvist ${ }^{6 s}$ acreditam que a remissão da dor seja devida, em alguns casos, à reabsorção do disco herniado, citando a casuistica de Eckert e Decker que, em $25 \%$ dos casos, encontraram fibrose e revascularização, considerando essa fase como indício de involução e absorção.

A êsse respeito preferimos adotar a opinião de Delitala ${ }^{29}$, que não acredita no retrocesso definitivo e duradouro do disco herniado, pelas seguintes razões: a porção do disco que hernia por uma pequena fissura, seja em conseqüência de traumatismo intenso ou simplesmente por degeneração agravada por traumatismos pequenos e repetidos pelo efeito dos movimentos da coluna vertebral, aumenta progressivamente de tamanho, o que torna impossivel sua volta total ao espaco que ocupava; concomitantemente, pode haver formação de aderências entre o ligamento longitudinal posterior, a dura máter e a substância herniada; assim, as fases de remissão observadas nesses pacientes são devidas possivelmente a fenômenos de adaptação das raizes nervosas à compressão exercida pela hérnia (mudança de posição da raiz em relação à hérnia) como também à diminuição da tensão do disco herniado, ligada à diminuição do seu conteúdo em água e ao estado de integridade do ligamento longitudinal posterior.

Nessas circunstâncias, é lógico que a remissão seja temporária; com o decorrer do tempo, a sintomatologia dolorosa tende a reaparecer, complicando-se com déficits sensitivos e motores.

Inspeção e mobilidade da coluna vertebral - Na grande maioria das vêzes, o exame da estática e dinâmica da coluna vertebral fornece informações valiosas. Sempre que possivel, a posição erecta deve ser a escolhida, pois, nessa postura, acentuam-se alguns sinais que poderão auxiliar o diagnóstico. Os elementos que nos parecem mais importantes são os seguintes: 
a) Contratura muscular - A contratura dos músculos eretores da coluna lombar constitui sinal encontradiço (tabela 6), se bem que seja comum também a outras afecções, principalmente tumores intra-raquidianos, tumores ósseos e fraturas. A contratura pode ser não só palpável, mas também visível.

b) Diminuição ou ausência de lordose lombar — Em grande número de casos de hérnias de discos intervertebrais a lordose lombar diminui ou desaparece (tabela 6). É excepcional que a lordose se acentue em tais casos.

c) Escoliose - A escoliose antálgica ou postural também ocorre em determinado número de casos (tabela 6); ela será homóloga ou heteróloga conforme a convexidade esteja voltada para o lado afetado ou para o lado são. Segundo O'Connell ${ }^{77}$, no caso de estar a hérnia situada para fora da raiz, a escoliose será convexa para o lado da dor, postura essa que evita que a raiz cavalgue o ponto mais alto da hérnia, agravando a dor; nos casos de hérnias situadas em posição central em relação à raiz, a escoliose será, mais freqüentemente, côncava para o lado da dor.

d) Limitação dos movimentos da coluna lombar - Esta limitação varia conforme a intensidade da sintomatologia dolorosa: na fase aguda, nenhum movimento é possivel, apresentando-se o paciente imobilizado no leito com a coluna rígida; em outras ocasiões, é possivel verificar a amplitude dos movimentos, sendo mais importantes os de flexão, de extensão e de inclinação lateral. Na grande maioria dos casos, o movimento de flexão é extremamente limitado, determinando exacerbação da dor, pois, em virtude da posição excêntrica do núcleo pulposo, pelo fato de ser o anel fibroso menos espêsso no seu quadrante posterior e, também, pela pouca resistência oferecida pelo ligamento longitudinal posterior, principalmente nas suas porções laterais, nos movimentos de flexão da coluna lombar, o núcleo pulposo tende a deslocar-se para trás, aumentando o volume do prolapso, com conseqüente exacerbação da sintomatologia. O movimento de extensão da coluna vertebral tende a acentuar a lordose fisiológica lombar que, como vimos, muitas vêzes não existe nos pacientes com hérnia de disco intervertebral lombar, determinando acentuação da dor, principalmente da lombalgia. As inclinaçōes laterais habitualmente não provocam ou exacerbam as dôres nos casos de hérnias de discos intervertebrais lombares; entretanto, desde que exista escoliose, a tentativa de correção dessa posição exacerba consideràvelmente tais dôres.

e) Dor à pressão ou percussão dos músculos paravertebrais - Spurling ${ }^{95}$ considera como sinal de hérnia posterior de disco intervertebral o aparecimento ou exacerbação de dor local ou de dor referida na área de distribuição de uma raiz raquidiana lombar ao ser exercida pressão digital ou percussão das apófises espinhosas ou dos músculos paravertebrais ao nível do disco intervertebral herniado; embora não seja constante, quando presente, êste sinal constitui indício diagnóstico bastante seguro; nós o encontramos em 10/128 casos. 
Lordose lombar ausente ou diminuida

48 casos

Escollose

Contratura dos músculos paravertebrais

38 casos

Movimento da raque determinando ou exacerbando a dor $\begin{cases}\text { flexão } & 72 \text { casos } \\ \text { extensão } & 53 \text { casos } \\ \text { inclinacões } & 34 \text { casos }\end{cases}$

Tabela 6 - Incidência, em 103 casos, de contratura dos músculos paravertebrais, de angulação da coluna vertebral e da exacerbação da dor conseqüente à movimentacão da coluna lombar. Em 25 casos não foram pesquisados os elementos constantes nesta tabela porque êsses pacientes não podiam ficar na posição ortostática, seja devido à exacerbacão das dôres que essa atitude provocava, seja em virtude de perturbacões motoras graves dos membros inferiores.

\section{Exame neurológico}

Se, em muitas ocasiōes, a anamnese e o exame da coluna vertebral sugerem o diagnóstico de hérnia de disco intervertebral lombar, é o exame neurológico que informará qual a raiz submetida à compressão; comumente, uma só raiz está comprimida, mas um prolapso único pode comprimir duas raízes adjacentes do mesmo lado ou duas raízes, direita e esquerda, no mesmo nível. Em casos de prolapsos múltiplos, várias raízes podem ser comprimidas. Por essas razões o exame neurológico nem sempre é conclusivo no que diz respeito à localização exata da sede da herniação discal.

Em ordem de importância, o exame neurológico permite observar o seguinte:

a) Disestesias - A delimitação exata das áreas de distribuição destas sensações subjetivas permite relacioná-las ao sofrimento de uma ou mais raízes raquidianas; quando dependentes de irritação ou compressão das raizes $\mathrm{L}_{3}$ e $\mathrm{L}_{4}$ localizam-se, em geral, na face ântero-lateral ou ântero-medial da côxa e, excepcionalmente, na face interna da perna; quando há comprometimento da raiz $L_{5}$ as disestesias situam-se na face ântero-lateral da perna, no dorso do pé e no grande artelho; o sofrimento da raiz $\mathrm{S}_{1}$ determina 0 aparecimento de distúrbios sensitivos na face posterior da perna, no calcanhar, na face plantar e borda externa do pé e nos últimos artelhos. Em nossa casuística, disestesias foram assinaladas em 108/128 casos.

b) Alterações objetivas da sensibilidade - Desde os trabalhos de Sherrington e Foerster sabe-se que a secção de uma única raiz raquidiana não determina anestesia completa da pele na região de distribuição dessa raiz; conseqüentemente, nas hërnias de discos intervertebrais lombares em que uma única raiz está comprimida, é difícil delimitar a área exata dos distúrbios sensitivos objetivos.

Keegan ${ }^{5 \tau}$, em 300 portadores de hérnias de discos intervertebrais lombares, encontrou alteraçōes objetivas da sensibilidade em 146 casos; êste autor realça o fato de que as alteraçōes das sensibilidades superficiais nas compressões monorradiculares 
não são objetivadas num dermatoma inteiro, mas apenas nas porções distais, onde é menor a superposição com o território de distribuiçāo de raizes vizinhas.

Devemos lembrar que os mapas dos diversos dermatomas variam de autor para autor; nossos achados coincidem com os relatados por $\mathrm{O}^{\prime}$ Connell ${ }^{7 \tau}$ e Sicard e Léca ${ }^{24}$. Assim, as pequenas áreas de alterações das sensibilidades superficiais situadas na face ântero-lateral da perna e no grande artelho, correspondem a lesão da raiz $L_{5}$, ao passo que as localizadas na face posterior da perna, na borda externa do pé e nos últimos artelhos, dependem de lesões da raiz $S_{1}$. Faixas de hipo ou de anestesias circunscritas foram encontradas, em nossa casuistica, em 34/128 casos.

c) Alterações dos reflexos profundos - Como rotina devem ser pesquisados os reflexos aquileu e patelar. Norlén ${ }^{75}$ estudou as alterações dêstes dois reflexos no homem, durante o ato operatório, bloqueando com novocaína as raizes raquidianas lombares, chegando a conclusões importantes, como sejam: 1) na grande maioria das vêzes, o reflexo aquileu depende da integridade da raiz $\mathrm{S}_{1}$; 2) entretanto, a hérnia do quinto disco intervertebral lombar $\left(\mathrm{Lv}_{5}-\mathrm{Sv}_{1}\right)$ nem sempre altera o reflexo aquileu; 3 ) em alguns casos, a via aferente do reflexo patelar transita pela raiz $\mathrm{L}_{4}$ e, outras vêzes, pela raiz $\mathrm{L}_{3}$. Em nossa casuística os referidos reflexos profundos se apresentaram anormais em $54 / 128$ casos.

Entretanto, as alterações dos reflexos profundos nem sempre permitiram o diagnóstico topográfico do disco herniado (tabela 7), o que é explicável, na maioria das vêzes, pela variação das relações topográficas entre as herniações e as raízes raquidianas.

\begin{tabular}{lr}
\hline Quinto disco herniado (50 casos): & \\
Reflexos normais & 24 \\
Aquileu diminuido ou abolido & 25 \\
Patelar diminuido ou abolido & 1 \\
Quarto disco herniado (57 casos): & 37 \\
Reflexos normais & 19 \\
Aquileu diminuido ou abolido & 2 \\
Patelar diminuido ou abolido & \\
Terceiro disco herniado (3 casos): & 3 \\
Reflexos normais & 1 \\
Aquileu diminuido ou abolido & \\
Patelar diminuido ou abolido & - \\
Segundo disco herniado (1 caso): & - \\
Reflexos normais & \\
Aquileu diminuido ou abolido & 12 \\
Patelar diminuido ou abolido & 4 \\
Herrnias múltiplas (17 casos): & 1 \\
Reflexos normais & \\
Aquileu diminuido ou abolido & \\
Patelar diminuido ou abolido & \\
\hline \hline
\end{tabular}

Tabela 7 - Análise das alteraçóes dos reflexos profundos em 128 casos. Nos casos de hérnia do quarto disco houve alterações de dois reflexos no mesmo paciente em uma ocasião; o mesmo se deu em outro caso em gue havia herniacão do terceiro disco intervertebral lombar. 
d) Paresias ou paralisias - Tal como para a sensibilidade, a inervação motora de cada músculo é feita por várias raízes raquidianas, cada uma delas participando da inervação de vários músculos; disso decorre que déficits musculares podem ser devidos a lesão de uma ou de várias raízes, concomitantemente. Paresia ou paralisia no território dos dorsiflexores do pé e do grande artelho foi verificada com freqüência quando a raiz $L_{5}$ fôra lesada por uma hérnia discal ou por manipulação cirúrgica; ao contrário, assinalamos como rara a paresia dos músculos flexores plantares do pé e dos artelhos quando a raiz $S_{1}$ era comprometida pela primeira das causas relatadas. Nossos achados parecem confirmar o que dizem Sicard e Léca ${ }^{\mathbf{9 4}}$, segundo os quais o ramo anterior da raiz $\mathrm{S}_{1}$ possui apenas pequeno contingente motor, ao passo que, na raiz $L_{5}$, existiriam fibras motoras suficientemente importantes para suprir, com freqüência, a inervação do território de distribuição do ciaticopopliteo interno. Paralisias ou paresias nos territórios de inervação das raízes $\mathrm{L}_{3}$ e $\mathrm{L}_{4}$ são raramente observadas, como assinalam Rasmusen ${ }^{86}$ e Spurling ${ }^{95}$. Paresias ou paralisias nos territórios de distribuição monorradicular de raízes raquidianas lombossacras ocorreram em 14/128 de nossos casos.

Paraparesias ou paraplegias que se instalam abruptamente após um esfôrço físico ou depois de um traumatismo vertebral, nos territórios de inervação das últimas raizes lombossacras, acompanhadas de perturbações esfincterianas, constituem um quadro neurológico conhecido, tendo como fator etiológico, na maioria das vêzes, o prolapso maciço de discos intervertebrais lombares no canal raquidiano.

Por vêzes, a dor radicular sùbitamente desaparece e é substituída, nesse mesmo território, por paresias ou paralisias acompanhadas de alteraçōes objetivas da sensibilidade. Tal fato foi encontrado por Guillaume e col. ${ }^{46} \mathrm{em}$ 22 casos numa revisão de 2.000 pacientes operados.

Se bem que menos freqüentes, casos há em que, na vigência de uma sintomatologia dolorosa lombar e/ou radicular, sùbitamente se instalam paraparesias ou paraplegias acompanhadas de alterações esfincterianas, constituindo a sindrome da cauda eqüina, quadro clínico bem estudado por Jennet 55 .

A sindrome da cauda eqüina, como início da afecção, é extremamente rara, pois, em geral, instala-se em pacientes já com referências pregressas de lombalgia, como verificamos em 4 casos de nossa casuística. Entretanto, após traumatismos violentos pode instalar-se êsse quadro em virtude da retropulsão maciça de um ou mais discos intervertebrais (Schneider ${ }^{91}$ ).

e) Sinais que aparecem pelas modificações da pressão do líqüido cefalorraquidiano ou que são devidos ao deslocamento das raizes e à compressão de músculos - Certas manobras que alteram bruscamente a pressão do líqüido cefalorraquidiano podem modificar momentâneamente as relações topográficas entre o disco intervertebral herniado e a raiz raquidiana correspondente, exacerbando ou determinando o aparecimento da dor; é isto o que ocorre quando o doente tosse ou espirra ou quando se faz a compressão das jugulares (sinal de Viets-Naffziger). Em nossa casuística, o "sinal da tosse 
ou espirro" foi encontrado em 105/128 casos, ao passo que o sinal de VietsNaffziger ocorreu em $49 / 128$ casos.

Outras manobras desencadeiam ou exacerbam a dor pelo deslocamento das raizes. Assim, a elevação progressiva do membro inferior estendido, no indivíduo normal em decúbito dorsal, pode ser realizada sem dor até um ângulo de aproximadamente $90^{\circ}$ com a bacia; nos casos de hérnia dos últimos discos intervertebrais lombares comprimindo as raizes $L_{5}$ e/ou $S_{1}$, com essa manobra a dor aparece precocemente em virtude do deslocamento das raízes comprometidas. Em 108/128 casos de nossa casuística esta manobra foi positiva. Este sinal pode ser positivo, também, quando se eleva o membro são, exacerbando-se ou instalando-se a dor no membro contralateral (20/128 casos); Woodhall e Heyes ${ }^{107}$ explicam êste efeito pelo movimento concomitante da raiz oposta que, entrando em contacto com o disco prolabiado e sendo comprimida, determina dor. Nessas mesmas circunstâncias, a flexão brusca do pescoço (sinal de Neri) pode determinar o aparecimento ou a exacerbação da dor por um mecanismo de ascensão da dura máter e conseqüente aumento de tensão das últimas raizes lombares e sacras, particularmente devido à disposição longitudinal das mesmas (O'Connell 77). Em 34/128 casos de nossa casuística ocorreu o sinal de Neri.

A dor provocada pela pressão de certos pontos musculares ao longo dos trajetos dos troncos nervosos (pontos de Valleix) é freqüente nos casos de hérnias de discos intervertebrais lombares, sendo atribuivel ao sofrimento, por compressão, das raízes raquidianas (Elliott ${ }^{33}$, Sahlgren e Sjöqvist 90 e Norlén ${ }^{75}$ ). Em 93/128 casos de nossa casuística a compressão dos pontos de Valleix provocava dor.

\section{Exame do liqüido cefalorraquidiano}

O exame do líqüido cefalorraquidiano por punção lombar e, mesmo, a verificação da permeabilidade do canal raquidiano não têm valor decisivo, na grande maioria das vêzes, para o diagnóstico das hérnias intra-raquidianas dos discos intervertebrais lombares porque, em geral, as protrusões não são suficientemente grandes para determinar bloqueio do canal raquidiano. Endossamos êsse conceito de numerosos autores (O'Connell ${ }^{77}$, Claudius ${ }^{16}$, Larsen e Kristoffersen ${ }^{61}$, Spurling ${ }^{95}$, Lasierra ${ }^{62}$, Armstrong ${ }^{6}$, entre outros), pois apenas em pequena percentagem de nossos casos foi encontrado discreto aumento da taxa de proteínas ou alterações nas provas manométricas. Entretanto, êste exame deve ser feito quando a sintomatologia clínica imponha dúvidas quanto ao diagnóstico de hérnia de disco intervertebral ou quando houver suspeita de neoplasia bloqueando o canal raquidiano. Nessas contingências, a hiperproteinorraquia acentuada e as anormalidades eventualmente encontradas nas provas manométricas (Queckenstedt-Stookey) auxiliarão no diagnóstico diferencial. Nos casos de paraplegias crurais flácidas que se instalam de forma aguda ou subaguda, especialmente quando a anamnese revela a existência de traumatismo raquidiano, o exame de líqüido cefalorraquidiano é de grande importância para a diferenciação diagnóstica entre afecções bloqueantes do canal raquidiano - entre as quais se incluiriam, 
neste caso, as herniações discais múltiplas e maciças - e as hematomielias; como é óbvio, a conduta terapêutica será diferente nestas duas modalidades de afecções.

Costumamos pedir o exame de líqüido cefalorraquidiano nos casos em que suspeitamos de herniações múltiplas, ou naqueles em que a sintomatologia clínica imponha o diagnóstico diferencial com afecções do cone medular, com neoplasias tanto do estojo ósseo como das raízes raquidianas, ou com malformações e aderências inflamatórias.

Nos 128 casos que serviram de base para êste trabalho o líqüido cefalorraquidiano foi examinado em 47 vêzes, encontrando-se, em pequena percentagem de casos $(19,1 \%)$, discreto aumento da taxa de proteinas ou alterações das provas manométricas.

\section{Exame radiográfico}

Exame radiográfico simples - O valor do exame radiográfico da coluna lombossacra reside mais no fato de mostrar ou excluir processos patológicos que clìnicamente possam simular a presença de hérnia de disco intervertebral do que nas indicaçōes fornecidas por êste exame para comprovar a existência das herniações discais que, habitualmente, não são visibilizáveis; evidentemente, escapam a esta regra os casos em que o disco prolabiado está calcificado, sendo visibilizado pela radiografia (Epstein ${ }^{34}$, Andersen 4 , Lasierra ${ }^{62}$ ). Aqui será necessário lembrar que a dor lombar e/ou radicular pode ser o único sintoma de um processo intrínseco dos ossos da coluna vertebral, eventualidade em que o exame radiográfico tem indicação absoluta.

Não é nosso objetivo analisar tôdas as alterações que se processam na coluna vertebral lombar, relacionadas com a presença de prolapso discal; contudo, devemos lembrar que a diminuição do espaço entre as vértebras, embora possa ser correlacionado com a diminuição da altura do disco intervertebral em virtude de sua procidência parcial, não é constante (Lewin ${ }^{65}$, Armstrong ${ }^{6}$, Spurling ${ }^{95}$, Epstein ${ }^{34}$ ). Nossa experiência confirma êsse fato, da mesma forma que nos leva não dar grande valor à normalidade do exame radiográfico para a exclusão do diagnóstico de hérnia de disco intervertebral, pois, em 64/128 casos êste exame resultou inteiramente normal.

A diminuição do espaço entre as vértebras (pinçamento do disco intervertebral) não constitui sinal patognomônico de hérnia discal, pois é encontrável também quando o disco está em degeneração (Armstrong ${ }^{6}$, Epstein ${ }^{34}$, Nórlen ${ }^{75}$, Lasierra ${ }^{62}$, Lewin ${ }^{65}$, Delitala ${ }^{29}$ ). Em nossa casuística, sòmente em 19/128 casos encontramos a redução do espaço intervertebral correspondente ao disco prolabiado; Gillespie ${ }^{40}$, Epstein ${ }^{34}$ e Armstrong ${ }^{6}$ também assinalam a pequena incidência dessa alteração. Entretanto, é evidente que a associação de sintomatologia dolorosa radicular com diminuição do espaço ocupado pelo disco que é cruzado pela raiz comprometida constitui elemento importante para o diagnóstico de prolapso de disco intervertebral.

Exames radiográficos devem ser feitos para a exclusão de processos de outra natureza (fraturas, espondilolisteses, neoplasmas e tuberculose, entre outros). Alterações ostearticulares foram encontradas em 44 dos 128 casos, 
associadas às hérnias de disco. Em nossa casuística, anomalias congênitas (sacralização da quinta vértebra lombar ou lombarização da primeira vértebra sacra) se associavam ao prolapso do disco sỏmente em 11/128 casos; alguns autores (O'Connell ${ }^{77}$ e Andrew ${ }^{5}$ ) admitem que essas anomalias estejam em maior número de casos.

Radiologia contrastada - Alguns autores se opõem ao emprêgo de radiografias contrastadas pelos óleos iodados, sob a alegação de que estas substâncias determinam reações inflamatórias assépticas, que, por si mesmas, agravariam a sintomatologia das hérnias dos discos intervertebrais. Nossa experiência, que abrange mais de 500 exames desta natureza, permite afirmar a relativa inocuidade dessas substâncias. certo que, em alguns casos, ocorrem manifestações indicadoras de reação meníngea (cefaléia, rigidez de nuca e ligeira hipertermia), manifestações que regridem espontâneamente dentro de 24 ou, no máximo, 48 horas. Entretanto, êstes distúrbios são habituais em todos os casos em que substâncias estranhas de qualquer natureza sejam injetadas no canal raquidiano e, em geral, desaparecem sem deixar reliquats. São raros os casos em que a evolução mostra a ocorrência de sintomas que possam ser atribuídos, de maneira segura, a aracnoidites adesivas produzidas pela injeção intra-raquidiana de substâncias usadas para as radiografias contrastadas.

Dada a grande freqüência com que a lombalgia com ou sem radiculalgia é causada por hérnias de discos intervertebrais e dada a possibilidade de se determinar clìnicamente a raiz raquidiana cuja compressão é responsável pela sintomatologia, muitos cirurgiões aconselham prescindir do exame radiológico contrastado. Entretanto, se o exame clínico, diante de um caso com sintomatologia nítida, permite afirmar qual seja a raiz raquidiana comprimida, o mesmo não se dá quanto ao disco intervertebral herniado, o que é indispensável para a perfeita abordagem çirúrgica. A regra segundo a qual a radiculalgia no território inervado por $S_{1}$ corresponde à hérnia do disco lombossacro, e a que a de $\mathrm{L}_{5}$ corresponde a hérnia do disco intervertebral situado entre $L_{4}$ e $L_{5}$, comporta algumas exceções. Assim, casos há em que a compressão da raiz $S_{1}$ é devida a hérnia do quarto disco lombar $\left(L v_{4}-L v_{5}\right)$, e a de $L_{5}$, conseqüente ao prolapso do terceiro disco lombar $\left(\mathrm{Lv}_{3}-\mathrm{Lv}_{4}\right)$. A intervenção cirúrgica feita nestas contingências seria exploradora, pois obrigaria o cirurgião a expor 2 ou 3 discos e, assim mesmo, com a possibilidade de não encontrar a lesão procurada, que poderia estar situada em níveis mais altos. Sòmente a perimielografia permite exploração extensa do canal raquidiano em uma única sessão, positivando o diagnóstico. Outras eventualidades que justificam, a nosso ver, o emprêgo da radiografia contrastada como rotina são a coexistência de hérnias bilaterais do mesmo disco intervertebral ou a ocorrência de hérnias múltiplas em vários discos, com sintomatologia monorradicular.

A responsabilidade das hérnias de discos intervertebrais lombares na produção de lombalgias isoladas, só pode ser firmada mediante a contribuição do exame radiográfico contrastado, pois numerosas outras afeç̧ões se 
manifestam com sintomatologia dolorosa do mesmo tipo. Barbosa ${ }^{9}$, em excelente monografia em que estudou as relações topográficas entre raízes raquidianas e discos intervertebrais, sugere que as hérnias do primeiro, segundo e terceiro discos intervertebrais lombares, manifestando-se apenas por lombalgias, devem ocorrer com maior freqüência que a consignada na literatura médica; sua pouca freqüência deverá ser, em parte pelo menos, atribuída à limitação do emprêgo da radiografia contrastada.

$E$ inegável o valor dos dados fornecidos por êste exame para o diagnóstico topográfico do processo mostrando detalhes que a clínica não permitiria evidenciar; a relutância em aceitar a perimielografia como parte integrante da investigação radiológica não se justifica mesmo diante dos poucos casos registrados nos quais a injeção de Lipiodol pôde ser responsabilizada por ocorrências desagradáveis.

Para justificar ainda mais o emprêgo da perimielografia como complemento indispensável para a elucidação diagnóstica, podemos lembrar os casos de tumores intra-raquidianos com sintomatologia análoga à das hérnias de discos intervertebrais lombares, mas localizados em niveis mais altos; nesses casos, a utilização isolada dos dados clínicos teria conduzido a erros quanto à abordagem cirúrgica.

Afirmação freqüente é a de que existem muitos casos de hérnias de disco intervertebrais com perimielografia normal e que, por outro lado, têm sido obtidas perimielografias com imagens falsas, conduzindo a erros diagnósticos; a estas objeções apenas aparentes será respondido que os resultados certos dependem de boa técnica e de cuidadosa interpretação. Não se deve esperar que o diagnóstico seja feito apenas quando sejam obtidas imagens típicas, superponíveis às que se encontram nos livros e atlas de radiologia; por outro lado se, durante a observação do trânsito do contraste, o neurorradiologista se limitar a radiografar a primeira irregularidade que deparar, não se preocupando em verificar se se trata de imagem constante, é claro que correrá o risco de interpretar como imagem patológica uma deformação do contraste dependente de causas outras que não sejam hérnias de discos intervertebrais.

Podemos afirmar que, em todos os 571 casos que operamos até junho de 1957, encontramos herniações discais com a topografia mostrada pela perimielografia. A tabela 8 mostra os resultados obtidos nos 128 casos utilizados para êste trabalho:

\begin{tabular}{cr}
\hline Imagem perimielográfica & $N^{\circ}$ de casos \\
\hline & \\
Hérnias discais únicas póstero-laterais & 92 \\
Hérnias bilaterais do mesmo disco & 8 \\
Hérnias múltiplas & 9 \\
Hérnias medianas & 19 \\
\hline
\end{tabular}

Tabela 8 - Resultados gerais da perimielografia em 128 casos. 
Não temos experiência com outros meios de contraste usados por via subaracnóidea ou peridural, mas nossa impressão é a de que nenhum dêles apresenta vantagens sôbre o que usamos como rotina. Em 1948, Lindblom ${ }^{67}$ introduziu mais um método complementar para o diagnóstico das hérnias dos três últimos discos lombares : a discografia. Acreditamos, com Epstein ${ }^{34}$, que não se trata de método para emprêgo como rotina, pois nada prova que sua utilidade supere as complicações que podem advir da punção do disco intervertebral. Entre nós, o método tem sido usado por Queiroz Ferreira ${ }^{84}$.

Baseados numa casuística que julgamos satisfatória para permitir conclusões, pensamos que, até o presente momento, não existe outro exame subsidiário que supere a perimielografia como meio complementar para o diagnóstico das hérnias intra-raquidianas dos discos intervertebrais lombares.

\section{Diagnóstico diferencial}

As hérnias intra-raquidianas dos discos intervertebrais lombares determinam o aparecimento de sintomas e sinais que permitem, em determinadas ocasiōes, formular pelo menos um diagnóstico de probabilidade. O diagnóstico de certeza só pode ser feito quando, ao lado da sintomatologia clínica, puder ser obtido um dado objetivo, como seja o representado pela perimielografia.

Numerosas afecções podem manifestar-se com sintomatologia semelhante à das hérnias dos discos intervertebrais lombares; com algumas - certos processos ostearticulares, malformações, tumores ósseos, espondilolisteses, fraturas de lâminas vertebrais, mal de Pott - o diagnóstico diferencial é possivel mediante o exame radiográfico simples. Entretanto, será preciso lembrar que algumas destas afecções podem estar associadas a hérnias discais; isto acontece, por exemplo, em casos de espondilolistese, que pode ser complicada com o prolapso de um disco intervertebral situado também acima ou abaixo dêsse deslisamento (Armstrong ${ }^{6}$ ).

Existem outras afecções cuja sintomatologia pode conduzir a erros diagnósticos. Assim, sindromes radiculálgicas podem decorrer de compressão do plexo sacrolombar por inflamaçóes ou tumores de tecidos e órgãos da cavidade pélvica ou dos ossos da bacia (Odell e Key ${ }^{78}$, Bronson ${ }^{13}$ ); tumores que infiltram o plexo sacrolombar podem ocasionar distúrbios com distribuição segmentar, confundiveis com os das hérnias de discos intervertebrais. Denton e Scherril ${ }^{28}$ relatam um caso de sindrome ciática conseqüente a metástase de endometriose no nervo ciático. Young ${ }^{108}$, em 12 pacientes com sintomas que faziam pensar em hérnias intervertebrais lombares, verificou que, na realidade, se tratava de outros processos (osteoma do fêmur, abscesso de Brodie do fêmur, cistos de ovário, granuloma eosinófilo do osso ilíaco, tumor do cavo popliteo, mielomas múltiplos, osteite fibrosa do trocânter, condromiossarcoma do fêmur e artrite tuberculosa da articulação sacriliaca).

O diagnóstico diferencial entre prolapsos de discos intervertebrais e tumores intra ou extradurais também se impõe, para que se evitem erros de tática cirúrgica e de conduta terapêutica. Em geral, o prolapso de disco produz sintomas e sinais unilaterais, o exame radiológico da coluna lombar não mostra alterações de monta e o líqüido cefalorraquidiano è pràticamente normal, enquanto os neoplasmas provocam sintomas e sinais bilaterais, maiores alterações do líqüido cefalorraquidiano (grande aumento da taxa de proteínas) e bloqueios parciais ou totais do canal raquidiano. Entretanto, o diagnóstico diferencial baseado sòmente nesses elementos é precário, pois, se o prolapso discal fôr volumoso, atuará como um neoplasma; recìprocamente, um neoplasma de pequenas dimensões, produzindo 
sintomatologia clínica unilateral e discreta, associada a modificações discretas do liqüido cefalorraquidiano, poderá ser confundido com hérnia do disco intervertebral.

Nada há de característico para a diferenciação clínica entre prolapsos de discos intervertebrais e certas neoplasias intra ou extradurais (neurinomas, meningeomas), pois em ambos os casos a evolução pode ser prolongada durante anos, com sintomas permanentes ou intermitentes, sendo a incidência aproximadamente idêntica em relação à idade dos pacientes (Toumey, Poppen e Hurley ${ }^{102}$, Pennybacker ${ }^{81}$, Love ${ }^{69}$, De Sèze e Guillaume ${ }^{25}$ ). As mesmas considerações poderiam ser aplicadas aos cistos das raizes sacras (Tarlov ${ }^{83}$ ). Os neurinomas ou os meningeomas determinam o aparecimento de sintomatologia correspondente às raizes nas quais se instalaram ou comprimiram, tornando dificil a diferenciação com o sofrimento dessas mesmas raízes secundário à compressão por hérnias discais; se, por exemplo, fôrem encontrados sintomas dependentes de lesōes da raiz $\mathrm{S}_{1}$, isso não significa necessàriamente que a causa esteja situada na altura do disco lombossacro, pois um neurinoma dessa mesma raiz, ou um meningeoma em qualquer altura de seu trajeto intra ou extradural, pode ocasionar idêntica sintomatologia. Em nossa casuistica geral, êsse fato ocorreu algumas vêzes: em um caso o neurinoma estava situado na altura da primeira vértebra lombar $\left(\mathrm{Lv}_{1}\right)$; em outras duas vêzes havia sintomatologia dependente das raizes $\mathrm{L}_{3}-\mathrm{L}_{4}$ e os neurinomas estavam localizados na altura de $T_{v_{12}}$ e $L_{v_{1}}$; em outro caso, um meningeoma localizado ao niver de $\mathrm{Tv}_{12}$ manifestava-se com sintomas decorrentes da lesão da raiz $L_{5}$; finalmente, em outros 10 pacientes com neurinomas situados nas alturas de $\mathrm{Lv}_{1}$ ( 2 casos), $\mathrm{Lv}_{3}$ ( 7 casos) e $\mathrm{Lv}_{4}$ ( 1 caso) predominava a queixa de dor lombar com irradiação ocasional para os membros inferiores, sem dermatoma preciso. É evidente que, em tais eventualidades, só a perimielografia permitirá esclarecer a natureza e a localização do processo mórbido.

Também merece atenção, quanto ao diagnóstico diferencial, a artrite coxofemoral, que se pode manifestar clinicamente com sintomatologia tipo radicular no territórlo de $\mathrm{L}_{3}$ e $\mathrm{L}_{4}$. Obletz, Hyman, Lochie e Milch ${ }^{76}$ assinalam a distribuição da dor e estudam a inervação, expondo os resultados obtidos pela desnervação parcial que realizaram em casos de artrite coxofemoral.

A hipertrofia do ligamento amarelo bem como as ectasias venosas epidurais podem, em determinadas ocasiōes, constituir a causa de manifestações dolorosas de tipo radicular; além disso, essas alteraçōes freqüentemente se apresentam associadas às hérnias de discos intervertebrais lombares. Naffziger, Innman e Saunders ${ }^{74}$ estudaram as lesões do ligamento amarelo do ponto de vista das manifestações clínicas, concluindo que, embora não seja fácil, o diagnóstico diferencial com as hérnias de discos intervertebrais não tem maior importância, uma vez que a conduta cirúrgica é a mesma.

Entre as causas infecciosas que determinam radiculalgia nos membros inferiores é citada a sífilis. Entretanto, mesmo admitindo que as radiculites luéticas possam manifestar-se com essa sintomatologia, é dificil compreender como o processo possa permanecer localizado em uma ou duas raizes, não atingindo tôdas as raizes da cauda equiina.

Entre os fatôres tóxicos, o chumbo, o álcool, o fósforo e o arsênico podem determinar radiculites, polirradiculites ou polineurites; as formas localizadas no plexo lombossacro são raríssimas. Além disso, as neuropatias tóxicas sempre são acompanhadas de sinais dependentes de lesōes sediadas em outros órgãos, o que facilita o diagnóstico diferencial.

A distinção entre a neurite leprosa e as paralisias isoladas do ciaticopoplíteo externo conseqüentes a hérnias de discos intervertebrais constitui, por vêzes, dificil problema diagnóstico. Evidentemente, os casos que encerram tais dificuldades são aquêles em que a paresia ou paralisia no território do ciaticopopliteo externo se instalou lenta e progressivamente, tal como sucede em casos de hérnias de discos intervertebrais antigas, nos quais ao prolapso discal se juntaram aderências entre o invólucro da raiz raquidiana e os tecidos circunvizinhos. No diagnóstico diferencial, desempenham papel importante o exame dos troncos nervosos periféricos mos- 
trando espessamentos, a biopsia e a informação de çue o paciente teve convivência com hansenianos (O. Julião ${ }^{56}$ ).

A exigüidade congênita do canal raquidiano (Verbiest ${ }^{103}$ ) e a meningocele intrasacra (Backer ${ }^{8}$ ) também podem ocasionar sintomatologia semelhante à das hérnias de discos intervertebrais; a perimielografia facilita o diagnóstico diferencial.

\section{TRATAMENTO CIRURGICO}

Formulado clìnicamente o diagnóstico de prolapso de disco intervertebral lombar, deve ser tentada, inicialmente, terapêtica conservadora, pois é preciso lembrar que causas diversas podem determinar sintomatologia semelhante à das hérnias discais; a terapêutica conservadora deverá ser mantida apenas quando seja realmente eficiente ou pelo tempo necessário para a complementação dos exames confirmadores do diagnóstico exato. Terminada esta complementação e confirmado o diagnóstico e a sede da hérnia de disco intervertebral, deve ser indicado o tratamento cirúrgico.

O tratamento conservador impõe, entretanto, observação rigorosa do paciente, pois é importante recordar que um pequeno prolapso discal que esteja evolvendo bem mediante êste tratamento, repentinamente, pela ação de um esfôrço físico ou mesmo de simples contração muscular súbita - como a tosse ou o espirro (Voris ${ }^{104}$ ) - pode expandir-se ou mesmo, pela dilaceração do ligamento longitudinal posterior, pode destacar-se do disco intervertebral, constituindo o que tem sido designado como "hernie eclate" (Ectors ${ }^{31}$ ), "free fragment" (Peterson e Gray ${ }^{80}$ ), "free fragmentation" (Armstrong ${ }^{8}$ ). Como resultados destas ocorrências, podem instalar-se paraplegias crurais súbitas, com perturbaçōes esfincterianas ( $3 / 128$ casos em nossa casuística).

O desaparecimento das dôres verificado durante o tratamento conservador tem sido invocado como argumento pelos que são contrários ao tratamento cirúrgico. De fato, isso é aparentemente o suficiente nos casos em que há exclusivamente sintomatologia dolorosa subjetiva; no entanto, essa melhora é enganosa nos casos em que já existam distúrbios sensitivos objetivos que não regridem; a protelação do tratamento cirúrgico é prejudicial, pois podem ocorrer paralisias ou paresias decorrentes de lesōes vasculares afetando o suprimento sangüineo das raízes motoras (Guillaume e col. ${ }^{46}$ ). O seguimento cuidadoso dos casos com repetição de exames orienta no sentido da continuação ou interrupção do tratamento conservador.

Somos contrários, frontalmente, ao emprêgo de certos métodos intempestivos utilizados às vêzes como auxiliares do tratamento conservador, como sejam as manipulações ou as trações descontínuas. Essas manobras, mormente quando realizadas sob anestesia geral, podem ocasionar paraplegias ou monoplegias súbitas, resultantes da irrupção brusca do conteúdo discal no canal raquidiano (Krayenbühl e Zander ${ }^{59}$, Love ${ }^{70}$, Spurling ${ }^{95}$, Lewin ${ }^{65}$, Pennybacker ${ }^{81}$, entre outros).

As medidas a adotar no período de tratamento conservador devem ser subordinadas a dois principios fundamentais: a) proteção ao disco anormal, sendo evitado qualquer esfôrço físico por parte do paciente; b) imobilização, sendo evitado qualquer movimento entre as vértebras.

Essas exigências serão plenamente satisfeitas mediante a adoção de medidas simples, como sejam o repouso absoluto no leito, com proibição de qualquer movimento, inclusive o de elevar a cabeça e, eventualmente, a imobilização por meio de recursos ortopédicos. A inatividade no leito pode ser menos rigorosa, dependendo da intensidade das dôres; sempre será exigido, entretanto, que o paciente não realize movimentos de flexão da coluna lombar. A imobilização por meios de aparelhos ortopédicos será indicada sempre que seja necessário restringir ainda mais a atividade física do paciente; para êsse fim, podem ser usadas várias técnicas, desde a cinta de pano com barbatanas até o colête gessado. 
Já salientamos que a conduta cirúrgica deve ser adotada no tratamento das hérnias de discos intervertebrais lombares desde que o tratamento conservador não tenha dado resultados satisfatórios. Entretanto, deve ser ressaltado que essa conduta é subordinada a uma prova que objetive a presença da hérnia intra-raquidiana de disco intervertebral (perimielografia).

A sintomatologia permite, por vêzes, sòmente um diagnóstico de suposição de hérnia discal, ao passo que, em outras ocasiōes, ela é mais precisa, indicando também o provável nivel da lesão. Contudo, é exatamente nestes últimos casos que maior cautela é exigida do examinador, pois a existência de hérnias múltiplas, a ocorrência de tumores ou mesmo de lesões vertebrais com sintomatologia monorradicular representam fatôres de incerteza com os quais tanto os neurologistas como os ortopedistas ou neurocirurgiões se defrontam, mormente quanto à conduta terapêtica. Taptas e Bayulken ${ }^{97}$, Pennybacker ${ }^{81}$, Toumey e col. ${ }^{102}$, Grant e col. ${ }^{41}$ e muitos outros, sòmente operam os pacientes quando a perimielografia mostra o tipo e a sede das lesões.

Erros diagnósticos e de conduta no tratamento serão evitados pelo emprêgo de exames radiológicos contrastados: Toumey e col. ${ }^{102}$ referem 48 casos de tumores da cauda equiina que exibiam sintomatologia semelhante à de hérnias discais e nos quais a perimielografia elucidou a verdadeira etiologia do processo. Da mesma forma, Pennybacker ${ }^{81}$ mostra que, em $5 \%$ de 800 pacientes operados, se tratava de tumores da cauda eqüina. Em nossa casuistica geral de operações raquidianas lombares ( 585 casos) houve 14 casos de tumores $(2,3 \%)$ nos quais a sintomatologia clínica fazia pensar em hérnias de discos intervertebrais lombares.

Sintetizando, consideramos que a intervenção cirúrgica está indicada, após a realização da perimielografia, nos casos cuja sintomatologia dolorosa aguda não foi beneficiada com o tratamento conservador mantido durante uma a quatro semanas, ou naqueles que, apesar de evidenciarem melhora da sintomatologia dolorosa subjetiva, apresentarem distúrbios sensitivos objetivos ou déficits motores. Contraindicamos qualquer contemporização do ato cirúrgico nos casos em que o exame mostre a presença de sinais de comprometimento radicular, sejam sensitivos (hipoestesias ou anestesias) ou motores (paresias ou paralisias).

Conduta e técnica operatórias - Descobrir e suprimir a lesão causal, libertar a raiz ou as raizes comprimidas são os objetivos da intervenção; entretanto, nem sempre é suficiente a simples excisão da hérnia. A êste propósito é útil recordar que, acompanhando a protrusão discal, podem existir exostoses nas bordas vertebrais, ectasias venosas (8/128 casos), aderências entre a bainha dural das raízes raquidianas e o ligamento longitudinal posterior (30/128 casos), bem como hipertrofia do ligamento amarelo (29/128 casos); em suma, condições que, por si mesmas, podem ocasionar dôres. Estas condições podem ocorrer isolada ou associadamente, motivo pelo qual o ato cirúrgico deve ser o mais completo possível.

Em certos casos a exérese de hérnias de discos intervertebrais deve ser complementada com a seç̧ão de raiz raquidiana sensitiva. Baseados nas publicações de De Sèze ${ }^{26}$, Guillaume ${ }^{45,46}$, Coste ${ }^{19}$, Alajouanine e Thurel 1, 2, 3, Frugoni ${ }^{37}$, Carrot e David ${ }^{15}$, Barré ${ }^{11}$, Spurling ${ }^{95}$, De Sèze, Guillaume e 
Charbonnel ${ }^{27}$, O’Connell ${ }^{77}$, Sicard e Léca ${ }^{94}$ e em nossa casuística, cogitamos da radicotomia posterior: a) quando a bainha dural da raiz estiver extremamente aderente ao ligamento longitudinal posterior, apresentando-se macroscòpicamente alterada; b) quando a exérese do disco intervertebral nos parecer ter sido incompleta; c) quando houver lesão cirúrgica acidental da bainha dural, que não pôde ser reparada convenientemente; d) quando, nos casos de hérnias recidivantes, uma raiz raquidiana esteja englobada em tecido fibroso; e) quando persistam radiculalgias pós-operatórias; f) quando existir dor monorradicular persistente cuja etiologia não tenha sido esclarecida (prolapso no buraco de conjugação?).

É necessário, contudo, ressaltar que três condiçōes devem ser exigidas para a prática da rizotomia: a) que a síndrome dolorosa tenha topografia radicular precisa; b) que seja seccionada apenas uma raiz sensitiva; c) que se esteja absolutamente seguro de que a raiz a seccionar corresponde realmente ao dermatoma doloroso referido pelo paciente. Obtivemos excelentes resultados em 10 casos incluídos neste trabalho nos quais praticamos a rizotomia posterior (em 4 casos, devido a aderências cicatriciais pós-operatórias e, em 6 outros, por alteraçōes da bainha dural da raiz).

Sicard e Léca ${ }^{94}$, revendo os resultados de 176 radicotomias, assinalam desaparecimento total das dôres em 145 e resultados parciais em 20 casos, sendo que sòmente em 11 casos não houve desaparecimento da dor. Éstes autores assinalam ser nulo ou pequeno o déficit sensitivo resuitante da rizotomia posterior, sendo que, nessa última eventualidade, as alterações regridem geralmente em prazo variável entre um mês e um ano.

Interessante assinalar que Sicard e Léca ${ }^{94}$ praticaram a secção total da raiz $S_{1}$ sem determinar déficit motor no território inervado pelo nervo ciaticopopliteo interno. Nossa experiência é pequena quanto a êste tipo de operação; entretanto, também pudemos verificar, em 5 pacientes, que a seccão total da raiz $S_{1}$ não acarretou paralisias ou paresias no território inervado pelo nervo ciaticopopliteo interno. No que diz respeito à inervação motora dependente das raizes $L_{5}$ e $S_{1}$ deve-se, após os estudos de Sicard e Léca ${ }^{94}$, admitir que, na majoria das vêzes, a raiz anterior $S_{1}$ não contenha senão pequeno contingente motor, existindo, na raiz $L_{5}$, suplências suficientemente importantes para permitir, sem inconvenientes, a radicotomia total da primeira raiz sacra; entretanto, será preciso ter presente que a secção da raiz anterior de $L_{5}$ acarreta, em geral, paralisia no território do nervo ciaticopoplíteo externo.

Problema de realce é o relativo à artródese da coluna vertebral, operação complementar que, defendida por alguns e condenada por outros, representa talvez a única questão ainda discutível no tratamento cirúrgico das hérnias intra-raquidianas de discos intervertebrais lombares.

Não é nosso propósito analisar detidamente o assunto, mas não podemos deixar de referir opiniões de cirurgiōes eminentes que se manifestam a favor ou contrários à prática imediata dessa operação complementar. No primeiro grupo, encontram-se Barr ${ }^{7}$, Craig ${ }^{20}$, Davidoff ${ }^{24}$, Ovens e Williams ${ }^{79}$, Magnuson ${ }^{72}$, Compere ${ }^{18}$, Cloward ${ }^{17}$, entre outros; no segundo Dandy ${ }^{22}$, Gama ${ }^{38,39}$, Spurling ${ }^{95}$, Spurling e Granthan ${ }^{96}$, Raaf e Berglund ${ }^{85}$, Greenwood e col. ${ }^{42}$, Larsen e Kristoffersen ${ }^{61}$, Busch ${ }^{14}$, Armstrong ${ }^{6}$, Foltz e col. ${ }^{36}$. Colocamo-nos entre os do segundo grupo, isto é, entre aquêles que só indicam e realizam a artródese num tempo ulterior, quando a lombalgia persistente e intensa incapacita as pacientes para o trabalho. Armstrong ${ }^{6}$ enumera uma série 
de argumentos contra a artródese piaticada imediatamente após a exérese da hérnia de discos intervertebrais. Em 1952, uma comissão designada pela American Orthopaedic Association ${ }^{73}$, em estudo comparativo entre os resultados obtidos num grupo de doentes tratados pela excisão simples da hérnia discal e os de outro constituido de pacientes nos quais a artródese fôra realizada imediatamente após a remoção do disco herniado, chegou à conclusão de que "spine fusion can be performed at a later date, in those patients whose poor results warrant additional surgery".

Por vézes, a fratura de uma apófise articular (Sicard e Gaucher ${ }^{{ }^{33}}$ ) é a responsável por sintomatologia idêntica à das hérnias de discos intervertebrais. Nesse caso, a artródese tem indicação como operação complementar imediata.

Preocupados com o problema da lombalgia pós-operatória nos pacientes operados de hérnia de discos intervertebrais lombares e baseados nos trabalhos de Roofe 88 e de Wiberg ${ }^{106}$, aventamos a possibilidade de que êsse sintoma residual decorra de irritação do nervo sinuvertebral de Luschka. Assim, passamos a praticar, como ato complementar da extirpação de hérnias de discos intervertebrais, a electrocoagulação do ligamento longitudinal posterior, visando a destruir grande parte do referido nervo. Após ter iniciado essa prática, verificamos ter diminuído a freqüência da lombalgia pós-operatória.

No sentido de reduzir ainda mais a incidência dêsse fenômeno doloroso estamos realizando o desnervamento parcial das apófises articulares posteriores, com base em excelente trabalho de Lériche ${ }^{64}$ e Lazorthes-Gaubert ${ }^{63}$ sôbre a inervação sensitiva dessas articulações e ligamentos. $O$ tempo de observação ainda não permite conclusões definitivas, mas os resultados imediatos nos animam a continuar complementando nossas intervenções com êsse detalhe.

Para permitir a inspeção da face posterior de um disco intervertebral e, quando necessário, da porção funicular de uma raiz raquidiana, a via de acesso deve ser suficientemente ampla; o cirurgião deve ter campo suficiente para poder reconhecer a lesão ou as lesões que estão determinando a sintomatologia (Guillaume e col.44). O campo cirúrgico deve ser amplo também em superfície para que o exame de estruturas profundamente situadas não exija o emprêgo excessivo de afastadores, o que pode determinar roturas de fibras musculares e conseqüente fibrose, e mesmo, irritação do ramo posterior do nervo espinhal que inerva os músculos lombares (Wedel e col. ${ }^{105}$ ), e conseqüente lombalgia pós-operatória.

Outros principios atmbém devem ser obedecidos para evitar complicações pós-operatórias: nunca dar por encerrada a intervenção sem ter absoluta certeza de que a hemostasia está perfeita; nunca deixar de explorar, com estilete rombo o buraco de conjugação para que não passe despercebida uma compressão de raiz raquidiana nesse nivel.

Entre os diversos tipos de operações, a laminectomia parcial unilateral com abordagem por via extradural é a mais freqüentemente utilizada para a excisão de hérnias discais lombares. Procedemos à laminectomia parcial unilateral quando a hérnia, objetivamente demonstrada pela perimielografia, 
está em situação póstero-lateral, sendo constituida à custa dos discos entre $\mathrm{Lv}_{4}-\mathrm{Lv}_{5}$ e $\mathrm{Lv}_{5}-\mathrm{Sv}_{1}$.

Quando a lesão se encontrar em espaços intervertebrais superiores (em virtude da obliqüidade das lâminas e por serem elas demasiadamente curtas), ou quando a hérnia tiver localização mediana, ou ainda, quando a hérnia fôr bilateral de um mesmo disco, optamos pela laminectomia total de 2 ou 3 vértebras; a exérese das apófises espinhosas permite, nesses casos, amplo campo operatório, facilitando a exploração das raízes raquidianas e proporcionando fácil acesso à porção mediana anterior do canal raquidiano.

Utilizamos a laminectomia total também quando suspeitamos que se tenham destacado fragmentos de disco intervertebral, pois não é raro que tais fragmentos se desloquem, ocupando níveis superiores ou inferiores ao espaço de onde provieram (Ectors ${ }^{31}$ ). Entre nossos casos registramos $5 \mathrm{em}$ que ocorreu esta fragmentação discal com deslocamento de porções destacadas; em um dêles, no qual houve rotura do saco dural, o fragmento se alojou entre as raizes da cauda eqüina.

Preferimos colocar o paciente em decúbito ventral, com a mesa operatória formando ângulo para cima de cêrca de $130^{\circ}$, o que faz com que se alarguem os espaços intervertebrais. Entretanto, é necessário cuidado para que a compressão abdominal não seja excessiva, para evitar estase venosa e hemorragias epidurais abundantes que dificultam o ato operatório; êste inconveniente será evitado colocando coxins de areia sob a bacia do doente ou mediante o uso de suportes especiais. As posições em decúbito lateral ou sentada (Bradford ${ }^{12}$ ), utilizadas por alguns cirurgiões, são extremamente incômodas, fatigando o operador sem vantagens especiais para os pacientes.

Usamos anestesia geral que, além de suprimir totalmente a dor, o que é fator de tranqüilidade na sala operatória, subordina as mudanças de posição do paciente à vontade do cirurgião. Além disso, êsse tipo de anestesia permite relaxamento muscular mais completo, facilitando as manobras operatórias. Quando o relaxamento muscular não é satisfatório, utilizamos a curarização como complemento da anestesia.

Robertson e Peacher ${ }^{8 \pi}$ descrevem uma inovação na técnica operatória, consistindo na preservação do ligamento amarelo, que é recolocado após a retirada do disco herniado; essa manobra visa a prevenir a formação de aderências entre as rafzes raquidianas e as estruturas vizinhas. Acreditamos, entretanto, ser pouco provável que tal aconteça, pois, se a recolocação do ligamento amarelo evitasse a formação de aderências entre as raizes raquidianas e os músculos paravertebrais, é impossivel imaginar por qual mecanismo esta reposição conseguiria impedir a formação de aderências entre a bainha dural da raiz raquidiana e o ligamento longitudinal posterior.

Com o fim de evitar ou diminuir a possibilidade de aderências entre raizes raquidianas e estruturas vizinhas, utilizamos, como foi aconselhado por Ingraham e col. ${ }^{53}$, a interposição de lâminas de esponja de gelatina entre a bainha dural das raizes $e$ o ligamento longitudinal posterior, assim como entre o saco dural e os músculos paravertebrais. Não tivemos oportunidade de re- 
intervir em pacientes portadores de hérnias discais nos quais usamos estas precauções, de sorte que não pudemos objetivar os resultados. Entretanto, realizando outros tipos de intervenções nas quais, anteriormente, tinham sido usadas lâminas de esponja de gelatina, pudemos verificar que se formara fina membrana entre as estruturas nervosas e os tecidos circunvizinhos, constituindo aderências frouxas e fàcilmente removiveis.

De importância na cirurgia de discos intervertebrais é a abordagem exata do espaço ou espaços que correspondem ao disco ou discos herniados; em geral, guiados pela perimielografia, sabemos qual a altura exata do disco ou dos discos herniados, como também qual seja sua situação, mediana ou lateral. Entretanto, no ato operatório é, às vêzes, difícil saber se estamos explorando o espaço $L v_{4}-L_{5}$ ou o espaço $L v_{3}-L v_{4}$, ou mesmo o compreendido entre $\mathrm{Lv}_{5}-\mathrm{Sv}_{1}$. Para melhor orientação adotamos, como norma, expor a face posterior do sacro; dêsse modo e não existindo anomalias congênitas da coluna vertebral, o primeiro espđço situado para cima será o constituído pela última vértebra lombar e pela primeira vértebra sacra; dai para cima, a orientação é segura.

Reconhecido o espaço intervertebral que se deseja abordar e localizado o disco herniado, deve ser feita a exposição da raiz raquidiana comprimida; esta parte talvez constitua a mais dificil da operação, pois a raiz pode estar encarcerada entre o prolapso do disco, a lâmina vertebral, o ligamento amarelo e a articulação posterior que formam as paredes lateral e posterior do canal raquidiano. A bainha dural da raiz, por vêzes, está tão intensamente comprimida pelo abaulamento do ligamento longitudinal posterior que adquire uma coloração esbranquiçada semelhante à que é própria do referido ligamento; por êsse motivo, a identificação da bainha dural da raiz e seu isolamento da superfície do ligamento longitudinal posterior ao qual por vêzes está fortemente aderida, constitui manobra delicada, dado o risco da rotura do invólucro dural, ou mesmo, de lesão ou dilaceração parcial da raiz. Esses acidentes representam causas de insucessos pós-operatórios; quando ocorrem, praticamos sempre a rizotomia posterior quando se trata da raiz $\mathrm{L}_{5}$; eventualmente, fazemos a rizotomia total quando a raiz comprometida é a $S_{1}$. As pequenas fendas involuntàriamente ocasionadas no saco dural, se não puderam ser suturadas por dificuldades técnicas, serão tamponadas com fragmentos de músculos ou com espuma de gelatina.

A exposição do disco herniado constitui o tempo seguinte da operação, sendo feita mediante o deslocamento da raiz raquidiana revestida de sua bainha dural e, eventualmente, também do saco dural para a linha mediana. Adotamos sempre essa conduta, mesmo nos casos em que a hérnia está situada em correspondência com o ângulo interno formado pela bainha dural da raiz e o saco dural. O afastamento lateral da bainha dural da raiz ocasiona maior número de vêzes os acidentes acima relatados. É freqüente, nesse tempo operatório, ocorrerem hemorragias venosas abundantes, que forçam alguns cirurgiōes não habituados com êsse tipo de cirurgia a suspende- 
rem a intervenção; entretanto, êsse sangramento é fàcilmente dominado pela electrocoagulação ou pelo tamponamento.

Caso não seja vista a hérnia discal mesmo depois de afastada a raiz raquidiana com sua bainha dural para a linha mediana, e mesmo que sejam encontradas ectasias venosas, que por vêzes constituem o único achado operatório, o cirurgião deverá continuar sua exploração até o buraco de conjugação, que será sondado com estilete rombo. Caso exista prolapso discal nesse nivel, torna-se necessária a apofisectomia ou facetectomia (Hirsch 49); com isso será possível libertar a raiz raquidiana de eventual encarceramento e extirpar a parte herniada do disco intervertebral (Hyndman ${ }^{51}$ ); quando menos, o buraco de conjugação será alargado (Salem ${ }^{89}$, Hadley ${ }^{47}$ ).

Havendo hérnia discal, duas eventualidades podem ocorrer: 1) abaulamento simples do ligamento longitudinal posterior; 2) dilaceração do ligamento longitudinal posterior com projeção parcial da hérnia discal para o interior do canal raquidiano. No primeiro caso, incisa-se circularmente a parte abaulada do ligamento longitudinal posterior; com isso, em geral o disco herniado se projeta para trás, o que facilita sua extirpação, que será completada pela curetagem do espaço intervertebral, procurando-se remover a maior parte do disco lesado (Dandy ${ }^{23}$, Love ${ }^{71}$, Key e Ford ${ }^{58}$, Echols ${ }^{30}$, Busch $\left.{ }^{14}\right)$. E admitido que esta extirpação ampla evita recidivas.

Neste tempo operatório é necessário grande cautela para evitar grave acidente: a lesão dos grandes vasos situados na porç̃o anterior da coluna vertebral, e conseqüente hemorragia interna, que pode ser fatal, ou então a formação de aneurismas arteriovenosos, cuja sintomatología só aparecerá tardiamente. A êste propósito será interessante referir trabalho publicado por Harbison 48 no qual o autor, por ter tido a oportunidade de operar um caso de fistula arteriovenosa devida a ferimento dêsses vasos durante a remoção do quarto disco lombar, promoveu um inquérito entre hábeis cirurgiōes norte-americanos, conseguindo reunir 30 casos de acidentes dessa natureza. A mortalidade referida em conseqüência dêsses acidentes é bastante elevada $(30 \%)$. Em nossa prática jamais tivemos complicações dessa natureza.

Nos casos em que a hérnia discal provoca rotura do ligamento longitudinal posterior, a substância discal prolabiada pode permanecer acolada ao disco do qual provém; entretanto, em alguns casos, fragmentos do disco podem desprender-se, ficando livres no espaço epidural. Tais fragmentos, únicos ou múltiplos, podem migrar no espaço epidural, localizando-se anteriormente ou lateralmente ao saco dural. Em certas eventualidades, porções discais fragmentadas podem romper o saco dural e penetrar no espaço subaracnóideo.

Têm sido assinalados casos em que fragmentos discais, deslocando-se para cima ou para baixo do nível do qual provieram, podem ser a causa da persistência de sintomatologia após o ato operatório. $O$ cirurgião deve ter em mente essa possibilidade para não deixar de investigá-la e eliminá-la. Casos dessa natureza figuram no presente trabalho $(5 / 128)$ e nos de Ectors e Tolosa ${ }^{32}$, Tartarini e Candelero ${ }^{99}$, Barraquer Ferré e Obiols ${ }^{10}$.

Removida a causa ou as causas que motivaram a sintomatologia e após hemostasia perfeita, o campo operatório deve ser lavado repetidas vêzes com 
soluto fisiológico morno, a fim de remover coágulos ou pequenos fragmentos de tecidos que poderiam contribuir para facilitar a formação excessiva de tecido cicatricial. $O$ ato operatório será terminado com a electrocoagulação do ligamento longitudinal posterior; ùltimamente, temos praticado também a desnervação parcial da articulação posterior; como já dissemos, estas últimas precauções visam a excluir a ação do nervo sinuvertebral de Luschka, ao qual atribuímos, em grande número de vêzes, a incidência ou persistência de lombalgia pós-operatória.

Cuidados no pós-operatório - O tratamento pós-operatório e o seguimento são fatôres importantes para o restabelecimento rápido dos pacientes. Também neste particular existem duas normas, ambas aconselhadas por cirurgiões com grande experiência. A primeira, ordenando a mobilização precoce do paciente, tanto ativa como passiva, desde os primeiros dias do pós-operatório; a segunda, não permitindo o exercício muscular e a atitude erecta senāo após a terceira semana. Somos de opinião que os exercicios musculares com os membros inferiores deverão ser iniciados precocemente, desde o segundo dia do pós-operatório, pois, além de úteis para impedir a ocorrência de flebites, tais movimentos permitem ao paciente certificar-se de que os mesmos podem ser realizados sem déficits; mesmo quando existirem distúrbios motores, seja como complicação do ato operatório, seja como conseqüência da afecção que motivou a intervenção, tais movimentos possibilitarão mais rápida recuperação. Permitimos ao paciente levantar-se geralmente após o 80 ou $10^{\circ}$ dia, iniciando outra série de exercícios visando a robustecer os músculos eretores da coluna. Em geral, após o $6^{\circ}$ mês a grande maioria dos pacientes já não refere dôres.

\section{RESULTADOS}

Dos 128 casos registrados nesta tese, 46 tiveram seguimento pós-operatório de um a dois anos; 46 foram controlados dois anos ou mais após a intervenção; 36 foram observados por mais de quatro anos depois da intervenção cirúrgica.

Os resultados foram considerados à luz dos seguintes elementos: a) total desaparecimento da sintomatologia dolorosa ou de alterações sensitivomotoras; b) persistência ou incidência de dor lombar, permanência ou agravação da dor nos membros inferiores e persistência de déficits sensitivos ou motores.

Esses resultados foram catalogados como bons (100 casos), quando os pacientes, um ano ou mais depois da intervenção cirúrgica, não apresentaram dôres espontâneas ou provocadas nem déficits motores ou sensitivos; como regulares (14 casos) quando os doentes continuaram, um ano após a operação, a se queixar de dôres atenuadas ou quando o exame neurológico mostrou a persistência de discretos déficits motores ou sentivos; como maus (14 casos) nos casos em que, um ano após a intervenção cirúrgica, havia dôres intensas ou acentuados déficits motores ou sensitivos.

Nos 100 casos cujos resultados foram considerados bons houve total desaparecimento da dor lombar e/ou nos membros inferiores, espontânea ou provocada. Neste grupo estão incluídos 27 dos 34 pacientes que apresenîvam alterações sensitivas objetivas antes da intervenção e nos quais estas 
alterações desapareceram no prazo de um ano após a operação. Também figuram neste grupo 10 casos nos quais a rizotomia posterior foi realizada como complemento da intervenção para a excisão das hérnias e que apresentaram, no pós-operatório imediato, distúrbios sensitivos objetivos; nestes 10 casos, tôdas as alterações atribuíveis à rizotomia tinham desaparecido um ano após a intervenção. Regressão total das perturbações motoras nos territórios dos nervos ciaticopoplíteos externo e interno, foi assinalada em 9 dos 14 casos que apresentavam essas alterações antes da operação e em 5 casos em que elas decorreram da intervenção cirúrgica. Também figura neste grupo um caso de síndrome da cauda eqüina no qual houve regressão completa da sintomatologia no decorrer de um ano após a intervenção cirúrgica.

Nos casos cujos resultados foram considerados regulares (14), persistia, um ano após a operação, lombalgia atenuada em 4 casos ou dor nos membros inferiores, também atenuada, em 4 outros. Em 4 casos que apresentavam alterações sensitivas objetivas (monorradiculares), tais alterações persistiram, embora atenuadas. Em 2 casos com alterações motoras isoladas nos territórios dos ciaticopoplíteos, houve regressão acentuada do déficit motor.

No último grupo cujos resultados foram considerados maus (14), em 6 casos havia intensa dor lombar um ano após a intervenção e, em 2, a dor persistiu nos membros inferiores. Em 3 outros casos houve persistência de acentuado déficit sensitivo-motor do tipo monorradicular. Nos 3 pacientes restantes, que apresentavam paraplegia no pré-operatório, sỏmente houve discreta regressão das alterações da sensibilidade e da motricidade, havendo também alguma melhora no contrôle dos esfincteres.

E oportuno assinalar que, dos 110 (110/128) doentes com lombalgia preexistente ao ato operatório, em 60 foi realizada a electrocoagulação do ligamento longitudinal posterior; em 45 dêsses casos a lombalgia desapareceu dentro de um período de três meses após a operação; em 11 casos êsse sintoma sơmente desapareceu entre três e dez meses após a intervenção cirúrgica; em 4 casos perdurou além de um ano.

Nos pacientes em que havia lombalgia pré-operatória e nos quais não foi feita a electrocoagulação $(50 / 110)$, em 10 casos a dor persistiu num período de um a três meses após a operação; em 34, êsse sintoma desapareceu entre três e onze meses; em 6, perdurou além de um ano.

Dos 18 pacientes (18/128) que não apresentavam lombalgia antes da operação, em 9 foi realizada a electrocoagulação; em 3 dêsses casos ocorreu, logo após a operação, lombalgia que desapareceu no periodo de um a três meses; nos 6 outros não ocorreu lombalgia, tanto no pós-operatório imediato como ulterior. Nos 9 pacientes restantes, nos quais não havia lombalgia preexistente à operação e nos quais não foi feita a electrocoagulação, houve incidência dêsse sintoma no pós-operatório; em 5 casos essa dor desapareceu num período entre um e três meses após a intervenção; em 4, êsse sintoma persistiu durante periodos variáveis de três a onze meses após a intervenção. 
Desta maneira, lombalgias persistiram em 10/110 pacientes além do período de 12 meses depois da operação: 4 (6,6\%) dêsses casos correspondem ao grupo de 60 pacientes nos quais foi feita a electrocoagulação do ligamento longitudinal posterior, e os demais $6(12,0 \%)$ pertencem ao grupo de 50 em que essa complementação não foi realizada. Essa diferença se acentua ainda mais se analisarmos êsses resultados no total dos pacientes (128) em face do tempo de desaparecimento da dor durante o decorrer do período de um ano de pós-operatório e da intensidade dêsse sintoma além dêsse período de tempo, nos dois grupos de doentes.

Assim, dos 69/128 casos nos quais foi feita a electrocoagulação do ligamento longitudinal posterior, em $6(8,6 \%)$ não houve incidência de dor no pós-operatório imediato; em $48(69,5 \%)$, a dor desapareceu entre um a três meses de pós-operatório; em $11(15,9 \%)$, entre três e dez meses. Esse sintoma permaneceu atenuado além de um ano em 3 casos $(4,3 \%)$ e acentuado em $1(1,4 \%)$.

Nos pacientes nos quais não foi feita a electrocoagulação (59/128), em $15(25,4 \%)$ a dor desapareceu entre um e três meses de pós-operatório; em 38 casos $(64,4 \%)$, entre três e onze meses. Esse sintoma permaneceu atenuado além de um ano em 1 caso $(1,6 \%)$ e acentuado em 5 outros $(8,4 \%)$.

Dos 117 (117/128) doentes com dôres nos membros inferiores preexistentes ao ato operatório, em 78 (10 rizotomias) houve regressão dêsse sintoma no periodo de três meses após a intervenção; em 33, a dor desapareceu no período de três a dez meses; em 6 , perdurou além dêsse período de observação. Nos restantes 11 casos (11/128), nos quais não havia manifestação dolorosa nos membros inferiores no pré-operatório, não se registrou ocorrência de tais dôres após a operação.

Em 68/128 casos foi interposta lâmina de fibrina isolando a bainha dural da raiz raquidiana das formações vizinhas; dêsses casos, em um único houve persistência de dor atenuada um ano após a operação.

Em 7 casos (7/128), houve necessidade de novas intervenções dentro do período de um ano após a primeira intervenção; em nenhum dêles por reincidência da hérnia discal operada ou por herniação de outra parte dêsse mesmo disco. A necessidade de reintervenção foi imposta, nesses 7 casos, respectivamente: para retirada de corpo estranho (1); para desfazer aderências cicatriciais (3); por ocorrência de osteomielite (1); para extirpação de outras hérnias discais (2).

As paresias no território inervado pelo nervo ciaticopoplíteo externo observadas em 5 casos no pós-operatório imediato e possivelmente atribuíveis à manipulação e tração durante o ato operatório, regrediram totalmente em espaço de tempo máximo de onze meses. Não foram observadas alterações no território do nervo ciaticopoplíteo interno como conseqüencia do ato cirúrgico.

Complicações operatórias ocorreram em 10 casos $(7,8 \%)$, em 5 dos quais foi necessária reintervenção, ao passo que, em 5 outros, os distúrbios pósoperatórios foram atribuídos a manipulação de raízes raquidianas. 
A rizotomia posterior $\left(L_{5}\right)$ foi realizada 10 vêzes, não tendo havido, no pós-operatório tardio e em decorrência dêsse complemento operatório, complicações que pudessem comprometer os bons resultados das excisões discais.

Dos 4 casos que apresentavam síndrome de cauda eqüina, em um só houve regressão total da sintomatologia e dos déficits neurológicos que existiam antes da intervenção.

Alterações do reflexo aquilleu foram registradas no pós-operatório em 28 casos, seja quando a intervenção visou exclusivamente ao quinto disco intervertebral (18 casos) ou quando foi manipulado o quarto disco intervertebral lombar (10 casos). Entretanto, as alterações dêsse reflexo, em conseqüência tanto das protrusões discais (51) como do ato operatório (28) e que persistiram em 35 casos após um período de 12 meses depois da intervenção, não foram consideradas para a avaliação dos resultados globais, pois tais alterações de reflexos elementares não concorreram para agravar subjetivamente o estado dos pacientes, cujas atividades motoras, voluntárias ou automáticas, não foram prejudicadas.

\section{RESUMO E CONCLUSOES}

O tratamento cirúrgico das hérnias de discos intervertebrais lombares tem indicações precisas e os resultados dependem de condições que devem ser convenientemente satisfeitas.

Nos casos em que só existe sintomatologia dolorosa subjetiva que não regride com o tratamento conservador, a intervenção cirúrgica deve ser condicionada à comprovação diagnóstica mediante um dado objetivo, qual seja a radiologia contrastada, que não só informa quanto à existência e situação de prolapso discal, como permite o diagnóstico diferencial com outras afecções.

Nos casos em que, além da sintomatologia dolorosa subjetiva, existem sintomas objetivos sensitivos e/ou motores, indicando sofrimento das raízes raquidianas, o tratamento cirúrgico tem indicação absoluta, devendo $o$ ato operatório ser precedido de exame radiológico contrastado.

Não deve haver qualquer contemporização no ato cirúrgico quando a sintomatologia plurirradicular e de caráter agudo fizer suspeitar da ocorrência de retropulsão maciça de discos intervertebrais.

Quanto à tática cirúrgica, deve ser feita laminectomia parcial unilateral quando o prolapso discal ocupar situação póstero-lateral, na altura dos espaços $L v_{4}-\mathrm{Lv}_{5}$ e $\mathrm{Lv}_{5}-\mathrm{Sv}_{1}$; quando o prolapso estiver situado em níveis mais altos ou quando estiver em situação mediana ou, mesmo, quando se tratar de herniações bilaterais de um mesmo disco intervertebral, deve ser feita a laminectomia total, para evitar trações exageradas sôbre as raízes raquidianas, trações que podem ocasionar seqüelas sensitivo-motoras irreversiveis.

O cirurgião deve considerar que seu alvo principal é suprimir as causas de compressão de raízes raquidianas; para isso, deve excisar o disco intervertebral herniado e, eventualmente, fazer a exérese de bordas escleróticas das vértebras; a excisão do disco lesado deve ser tão completa quanto possívl, mediante curetagem, para evitar recidivas. 
Quando a herniação discal estiver situada no buraco de conjugação, deve ser feita a facetectomia, sendo a intervenção completada com artródese para imobilização.

Para a exposição de hérnia discal, a bainha dural da raiz raquidiana deve sempre ser deslocada para a linha mediana, qualquer que seja a situação do prolapso, pois, dêsse modo, são diminuidas as possibilidades de lesões traumáticas da raiz que está sendo manipulada.

Fragmentos livres de disco intervertebral no espaço epidural devem ser extirpados; o cirurgião deve ter presente a possibilidade da existência de tais fragmentos em niveis situados imediatamente acima ou abaixo do disco herniado.

A rizotomia posterior deve ser praticada quando existir fibrose intensa da bainha dural de raízes raquidianas e, eventualmente, quando a excisão da hérnia discal não fôr julgada satisfatória; a rizotomia posterior deve ser feita, também, tôdas as vêzes em que a reparação de uma lesão acidental da bainha de uma raiz raquidiana não tenha sido satisfatória.

A electrocoagulação do ligamento longitudinal posterior, visando à destruição da maior parte do nervo sinuvertebral de Luschka, deve complementar a operação para diminuir a persistência ou a incidência de lombalgias.

A hemostasia deve ser perfeita para diminuir a formação de tecido cicatricial, causa de sintomatologia dolorosa no pós-operatório. Com êsse mesmo intuito deve ser interposta lâmina de esponja de gelatina isolando a bainha dural da raiz raquidiana das formações circunvizinhas.

Neste trabalho são apresentados os resultados obtidos em 128 casos, escolhidos entre 571 pacientes operados de hérnias intra-raquidianas de discos intervertebrais lombares; êstes 128 casos foram selecionados por terem seguimento de um ano, no mínimo, para permitir boa avaliação dos resultados.

Foram considerados como bons tão sòmente os resultados obtidos nos pacientes que, um ano após a intervenção cirúrgica, não apresentavam qualquer sintoma objetivo ou subjetivo decorrente da afecção (100/128 casos, ou sejam 78,1\%); como regulares, aquêles em que houve apenas melhoras $(14 / 128$ casos, ou sejam $10,9 \%)$; como maus aquêles em que os pacientes não foram beneficiados com a intervenção (14/128 casos, ou sejam 10,9\%).

Dentro de criteriosas indicações, as hérnias intra-raquidianas de discos intravertebrais lombares devem ser tratadas com métodos cirúrgicos; salvo casos excepcionais, tais operações devem ser feitas por neurocirurgiões.

\section{SUMMARY AND CONCLUSIONS}

\section{Herniated lumbar intervertebral discs: end-results of surgical excision in 128 cases.}

From a series of 571 patients with herniated lumbar intervertebral discs operated upon the author selected 128 cases that had been carefully observed during a period of at least one year. 
The results were classified as good, regular and poor ones. Good results, i.e., without any remaining signs or symptoms, were obtained in $78.1 \%$ (100/128) of the cases; regular results with remaining signs and symptoms, less evident than preoperatively, represents $10.9 \%(14 / 128)$ of the cases; no relief of the previous signs and symptoms was verified in $10.9 \%(14 / 128)$ of the cases.

The author emphasizes that surgical approach is indicated (1) when the conservative treatment is ineffective, (2) when sensory or motor deficits are evident and finally, (3) when acute damage of several nerve roots is present.

Myelography must always be added to the clinical examination since it will give the site and extension of the lesion as well as the elements for differential diagnosis.

Once indicated the operation must be carried out by trained neurosurgeon. Special attention is dedicated to the description of the technical details concerning the surgical act.

\section{REFERENCIAS BIBLIOGRAFICAS}

1. ALAJOUANINE, Th.; THUREL, R. - Hernie discale récidivante. Rev. Neurol., 78:51, 1946. 2. ALAJOUANINE, Th.; THUREL, R. - Le traitement chirurgical de la sciatique d'après 100 cas opérés. Rev. Neurol., 75:184, 1943. 3. ALAJOUANINE, Th.; THUREL, R. - Médecine ou chirurgie: sciatique et névralgie faciale. Rev. Neurol., 76:155, 1944. 4. ANDERSEN, A. - Modifications radiologiques dans le prolapsus discal. Acta Psychiat. et Neurol. Scandinav., 25:467, 1950. 5. ANDREW, J. - Sacralization: an aetiological factor in lumbar intervertebral disc lesions and a cause of misleading focal signs. Brit. J. Surg., 42:304, 1954. 6. ARMSTRONG, J. R. - Lumbar Disc Lesions. Pathogenesis and Treatment of Low Back Pain and Sciatica. Livingstone Ltd., Edinburgo e Londres, 1952. 7. BARR, J. S. - Ruptured intervertebral disc and sciatic pain. J. Bone a. Joint Surg., 29:429, 1947. 8. BACKER, G. - Intrasacral meningocele causing backache and sacral nerve pain. Proceded Staff Meet., Mayo Clinic, 27:231, 1952. 9. BARBOSA, T. R. - Região lombossacra. Considerações sôbre as relações das raizes nervosas com os discos intervertebrais. Estudo anátomo-radiológico. Bol. Col. Brasil. Cir., 29:41, 1957. 10. BARRAQUER FERRE, E.; OBIOLS, D. F. - Doble compresión de la coda de caballo por hernia discal libre, aberrante y estenosis discoligamentaria. Med. Clín. (Barcelona), 25:355, 1955. 11. BARRE, J. A. - Sur le traitment des sciatalgias rebelles par la section et résection intradure-mèrienne des racines sensitives en cause. Rev. Neurol., 74:221, 1942. 12. BRADFORD, F. K. - El problema del disco intervertebral en la Marina de Guerra. Rev. Radiol. y Fisiot., 12:37, 1945. 13. BRONSON, S. R. - Differential diagnosis between ruptured lumbar intervertebral disc and certain diseases of the spinal and peripheral nervous system. S. Clin. North America, 26:272, 1946. 14. BUSCH, E. - Myélographie. Indication de l'operation. Acta Psychiat. et Neurol. Scandinav., 25:484, 1950. 15. CARROTT, E.; DAVID, M. - Sur le traitement chirurgical des sciatiques rebelles. Rev. Neurol., 75:186, 1943. 16. CLAUDIUS, T. Prolapsus de disque et liquide céphalo-rachidien. Acta Psychiat. et Neurol. Scandinav., 25:465, 1950. 17. CLOWARD, R. B. - The treatment of ruptured lumbar intervertebral discs by vertebral body fusion. J. Neurosurg., 10:154, 1953. 18. COMPERE, E. L. - Fusion of the spine after removal of ruptured disc. J. Internat. Coll. Surg., 9:14, 1946. 19. COSTE, F. - Remarques sur le traitement des sciatiques. Rev. Neurol., 75:194, 1943. 20. CRAIG, W. M. - The role of protuded intervertebral disc in production of low back pain and sciatic pain. Rocky Mountain M. J., 39:98, 
1942. 21. DANDY, W. E. - Concealed ruptured intervertebral discs; a plea for the elimination of contrast mediums in diagnosis. J.A.M.A., 117:821, 1941. 22. DANDY, W. E. - Recent advances in the treatment of ruptured lumbar intervertebral discs. Ann. Surg., 118:639, 1943. 23. DANDY, W. E. - Improved localization and treatment of ruptured intervertebral discs. J.A.M.A., 120:605, 1942. 24. DAVIDOFF, L. M. - Modification in surgical treatment of herniated nucleus pulposus. Bull. New York Acad. Med., 19:657, 1943. 25. De SEZZE, S.; GUILlaume, J. - Sciatique récidivante évoluant pendant 8 ans sans aucun signe objectif, tardivement compliquée de crises douloureuses brachiales. Ablations de deux neurogliomes intra-rachidiens, lombaire et cervical. Rev. Neurol., 75:145, 1943. 26. De SEZE, S. - Le traitement chirurgical des sclatiques rebelles. Rev. Neurol., 75:187, 1943. 27. De SEZE, S.; GUILlAAUME, J. M.; CHARBONNEL, A. - Section intraduremérienne d'une racine posterieure $\left(L_{5}\right)$ comme traitement d'une sciatique discale très rebelle. Rev. Neurol., 74:223, 1942. 28. DENTON, R. O.; SCHERRILL, J. D. - Sciatic syndrome due to endometrioses of the sciatic nerve. J. Bone a. Joint Surg., 2:415, 1955. 29. DELITALA, F.; BONOLA, A. - Ernia del Disco e Sciatica Vertebrale. L. Capelli, Bolonha, 1949. 30. ECHOLS, D. H. - Surgical treatment of sciatica due to rupture of an intervertebral disc. S. Clin. North America, 23:1335, 1943. 31. ECTORS, L. - La hernie discale libre. Acta Neurol. et Psychiat. Belgica, 53:417, 1953. 32. ECTORS, L.; TOLOSA, E. - Hernie discale libre luxée à la face posterieure du cul-de-sac dural. Syndrome de la queue de cheval. Acta Neurol. et Psychiat. Belgica, 53:433, 1953. 33. EllioT, F. A. - Citado por Norlen ${ }^{73}$. 34. EPSTEIN, B. S. - The Spine. A Radiological Text and Atlas. Lea \& Febiger, Filadélfia, 1955. 35. FALCONER, M. A.; Mc GEORGE, M.; BEGG, A. C. - Observations on the cause and mechanism of symptom-production in sciatica and low back pain. J. Neurol. Neurosurg. a. Psychiat., 11:13, 1948. 36. FOLTZ, E. L.; WARD, A. A.; KNOPP, L. M. - Intervertebral fusion following lumbar disc excision. J. Neurosurg., 13:468, 1956. 37. FRUGONI, A. G. Tratamiento quírúrgico de la ciática rebelde por hernia del disco intervertebral. Rev. A. M. Argent., 59:763, 1945. 38. GAMA, C. - Comunicação pessoal. 39. GAMA, I. J. - A cirurgia no tratamento da ciática. Amatus Lusitanus, 3:211, 1944.40. GILlESPIE, H. W. - Radiological diagnosis of lumbar intervertebral disc lesions: report of 160 cases. Brit. J. Radiol., 19:420, 1946. 41. GRANT, F. C.; AUSTIN, G.; FRIEDENBERG, Z.; HANSEN, A. - A correlation of neurologic, orthopedic and roentgenographic findings in displaced intervertebral disc. Surg., Gynec. a. Obst., 87: 561, 1948. 42. GREENWOOD Jr., J.; Mc GUIRE, T. H.; KIMBELL, F. - A study of the causes of failure in the herniated intervertebral disc operation. Analysis of 67 reoperated cases. J. Neurosurg., 9:15, 1952. 43. GUILlaumE, J. - Les indications de la radicotomie postérieure dans la sciatique rebelle. Rev. Neurol., 75:192, 1943. 44. GuIllaUME, J.; De SEZE, S.; MASSABOEUF — Syndrome de la queue de cheval par hernie du disque $L_{5}-S_{1}$. Rev. Neurol., 76:25, 1944. 45. GUILlaUME, J. - Remarques operatoires relatives à la sciatique discale. Rev. Neurol., 75:191, 1953. 46. GUIllaUME, J.; De SĖZE, S.; MAZARS, G.; DESPROGES, R. - La sciatique paralysante. Rev. Neurol., 93:685, 1955. 47. HADLEY, L. A. - Intervertebral foramen studies: foramen encroachment associated with disc herniation. J. Neurosurg., $7: 347,1950$. 48. HARBISON, S. P. - Major vascular complications of intervertebral disc surgery. Ann. Surg., 140:342, 1954. 49. HIRCH, C. - On lumbar facetectomies. J. Bone a. Joint Surg., 34:548, 1952. 50. HIRSCH, C. - Studies on the mechanism of low back pain. Acta Orthop. Scandinav., 20:261, 1951. 51. HYNDMAN, O. R. - Pathologic intervertebral disc and its consequences. Arch. Surg., 53: 247, 1946. 52. HYNDMAN, O. R.; STEINDLER, A. - Citados por Delitala e Bonola ${ }^{29}$. 53. INGRAHAM, F. D.; BAILEY, O. T. - The use of products prepared from human fibrinogen and human thrombin in neurosurgery. J. Neurosurg., 1:23, 1944.54. INMAN, V. T.; SAUNDERS, M. C. - Citados por Armstrong ${ }^{8}$. 55. JENNET, B. Study of 25 cases of compression of the cauda equina by prolapsed intervertebral discs. J. Neurol., Neurosurg. a. Psychiat., 19:109, 1956. 56. JULIXO, O. F. - Contribuição para o estudo do diagnóstico clínico da lepra nervosa. Tese, São Paulo, 1945. 57. KEEGAN, J. J. - Dermatome hypalgesia associated with herniation of 
intervertebral disc. Arch. Neurol. a. Psychiat., 50:67, 1943. 58. KEY, A.; FORD, T. - Experimental intervertebral disc lesion. J. Bone a. Joint Surg., 30:235, 1950.59. KRAYENBÜHL, H.; ZANDER, E. - Des hernies discales lombaires et cervicales. Documenta Rheumatol., 1:11, 1953. 60. KUSS, R.; De SEZE, S. - Citados por Thurel 101. 61. LARSEN, E. H.; KRISTOFFERSEN, K. - Follow-up of patients submited to operation for herniation of lumbar intervertebral disc. Acta Psychiat. et Neurol. Scandinav., supl. 108:217, 1956. 62. LASIERRA, A. P. — Sindromes Neurológicas en las Malformaciones y Lesiones Degenerativas del Estuche Cráneo-vertebral y su Tratamiento Neuroquirúrgico. Ed. Paz Montalvo, Madrid, 1956. 63. LAZORTHES, G.; GAUBERT, J. - Le syndrome de la branche postérieure des nerfs rachidiens. Presse Méd., 64:2022, 1956. 64. LÉRICHE, R. — Rôle de l'innervation sensitive des articulations et leur appareil ligamentaire dans la physiologie pathologique articulaire. Presse Méd., 38:417, 1930. 65. LEWIN, P. - The Back and its Disc Syndromes. Lea \& Febiger, Filadélfia, 1955. 66. LINDBLOM, K.; HULTQVIST, G. — Absorption of protuded disc tissue. J. Bone a. Joint Surg., 32:557, 1950. 67. LINDBLOM, K. Diagnostic puncture of intervertebral discs in sciatica. Acta Orthoped. Scandinav., $17: 231$, 1948. 68. LOVE, J. G. - Injuries of the intervertebral disc military service. War Med., 2:403, 1942. 69. LOVE, J. G. - Differential diagnosis of intraspinal tumors and protuted intervertebral discs and their surgical treatment. J. Neurosurg., $1: 275$, 1944. 70. LOVE, J. G. - The disc factor in low back pain with or without sciatic. J. Bone a. Joint Surg., 29:438, 1947. 71. LOVE, J. G. — Recurrent protusion of an intervertebral disc. Proc. Staff Met., Mayo Clin., 13:404, 1929. 72. MAGNUSON, P. B. - Intervertebral discs. Am. J. Surg., 67:228, 1945. 73. NACHLAS, W. End results of the treatment of herniated nucleus pulposus by excision with fusion and without fusion. J. Bone a. Joint Surg., 34:981, 1952. 74. NAFFZIGER, H. C.; INNMAN, V.; SAUNDERS, C. M. J. - Lesions of the intervertebral disc and ligamenta flava. Clinical and anatomical studies. Surg., Gynec. a. Obst., 66:288, 1938. 75. NORLEN, G. - On the value of the neurological symptoms in sciatica for the localization of a lumbar dise herniation. Acta Chir. Scandinav., supl. 95:8, 1944. 76. OBLETZ, B.; LOCHIE, M.; MILCH, E.; HYMAN, I. - Early effects of partial sensory denervation of the hip for relief of pain in chronic arthrites. J. Bone a. Joint Surg., 31:805, 1949. 77. O'CONNELL, J. E. A. - Protusions of the lumbar intervertebral discs. A clinical review based on five hundred cases treated by excision of the protusion. J. Bone a. Joint Surg., 33:8, 1951. 78. ODELL, R. T.; KEY, J. A. - Lumbar disc syndrome caused by malignant tumors of bone. J.A.M.A., 157: 213, 1955. 79. OVENS, J. M.; WILLIAMS, H. G. - Intervertebral spine fusion with removal of herniated intervertebral disc. Am. J. Surg., 70:24, 1945. 80. PATERSON, J. E.; GRAY, W. - Herniated nucleus pulposus: the free fragment. Brit. J. Surg., 39:509, 1952. 81. PENNYBACKER, J. - Lesion of lumbar intervertebral discs. J. Bone a. Joint Surg., 31:635, 1949. 82. PERMIN, P. - Le prolapsus discal et traumatisme lombaire. Acta Psychiat. et Neurol. Scandinav., 25:455, 1950. 83. PUTTI, V. - Lombartrite e Sciatica Vertebrale. Ed. Capelli, Bolonha, 1936. 84. QUEIROZ FERREIRA, S. - Novo processo de semiologia radiológica para evidenciar as lesões do núcleo pulposo. Arq. Méd. Municipais, 8:27, 1956. 85. RAAF, J.; BERGLUND, G. - Results of operations for lumbar protuded intervertebral disc. J. Neurosurg., 6: 160, 1949. 86. RASMUSEN, J. H. - Protrusion of the second lumbar intervertebral disc. J. Bone a. Joint Surg., 34:2, 1954. 87. ROBERTSON, R. C. L.; PEACHER, W. ' $\dot{x}$. - Herniated nucleus pulposus; improvement in operative technique. Bull. U.S. Army Med. Depart., 76:76, 1944. 88. ROOFE, P. G. - Innervation of annulus fibrosus and posterior longitudinal ligament, fourth and fifth lumbar level. Arch. Neurol. a. Psychiat., 44:100, 1940. 89. SALEM, E. - Low-back pain to narrowing of the intervertebral foramen. Bull. Hosp. Joint Dis., 8:187, 1947. 90. SCHALGREN, 2.: SJOQVIST, O. - Citados por Norién ${ }^{75}$. 91. SCHNEIDER, R. - Acute traumatic posterior dislocation of an intervertebral dise with paralysis. J. Bone a. Joint Surg., 31:566, 1949. 92. SCOTT, J. C. - Stress factor in the disc syndrome. J. Bone a. Joint Surg., 37:107, 1955. 93. SICARD, A.; GAUCHER, M. - Sciatique rebelle par frature d'une apophyse articulaire. Presse Méd., 54:412, 1946. 94. SICARD, A.; LECA, 
A. - La place de la radicotomie dans le traitement chirurgical des sciatiques. Presse Méd., 62:1737, 1954. 95. SPURLING, G. - Lesions of the Lumbar Intervertebral Disc. Charles C. Thomas, Springfield, 1953. 96. SPURLING, G.; GRANTHAM, G. E. - End results of surgery for ruptured lumbar intervertebral discs. A follow-up study of 337 cases. J. Neurosurg., 6:57, 1949. 97. TAPTAS, G. N.; BAYULKEN, F. - Discordances anatomo-cliniçues au cours de certaines sciatolgies par hernie discale. Presse Méd., 63:1394, 1955. 98. TARLOV, I. M. - Sacral Nerve-root Cysts. Another Cause of the Sciatic or Cauda Equina Syndrome. Charles C. Thomas, Springfield, 1953. 99. TARTARINI, E.; CANDELERO, G. - Su due casi di framento discale libero nello speco vertebrale. Sist. Nerv., 7:217, 1955. 100. TENUTO, A. R. - Conduta, achados cirúrgicos e "follow-up" a propósito de 48 casos de radiculalgia dos membros inferiores. Rev. Cir. de São Paulo, 16:51, 1950. 101. THUREL, R. La Douleur en Neurologie. Masson et Cie., Paris, 1951. 102. TOUMEY, J. W.; POPPEN, J. L.; HURLEY, M. T. - Cauda equina tumors as a cause of low-back syndrome. J. Bone a. Joint Surg., 32:249, 1950. 103. VERBIEST, H. - A radicular syndrome from developmental narrowing of the lumbar vertebral canal. J. Bone a. Joint Surg., 36:230, 1954. 104. VORIS, H. C. - Sudden extrusion of an intervertebral disc. Dis. Nerv. Syst., 6:80, 1945. 105. WEDEL, G.; FEINSTEIN, B.; PLATTLE, R. E. - Citados por Lasierra ${ }^{82}$. 106, WIBERG, G. - Back pain in relation to the nerve supply of the intervertebral disc. Acta Orthoped. Scandinav., 19:211, 1941. 107. WOODHALL, B.; HEYES, G. J. - The well-leg raising test of Fajersztajn in diagnosis of ruptured lumbar intervertebral disc. J. Bone a. Joint Surg., 432:786, 1950. 108. YOUNG, H. H. - Additional lesions simulating protruded intervertebral disc. J. Internat. Coll. Surg., 17:831, 1952.

Clínica Neurológica - Hospital das Clínicas da Fac. Med. da Univ. de São Paulo Caixa Postal 3461 - São Paulo. Brasil. 